$$
\begin{aligned}
& \text { المحاسبة هل هي مبادئ ومفاهيم أم قواعد وأحكام } \\
& \text { من منظور دولي } \\
& \text { الدكتور قاسم محسن الحبيطي } \\
& \text { أستاذ - قسم المحاسبة } \\
& \text { كلية الإدارة والاقتصاد - جامعة الموصل }
\end{aligned}
$$

Maher_shmam@yahoo.com

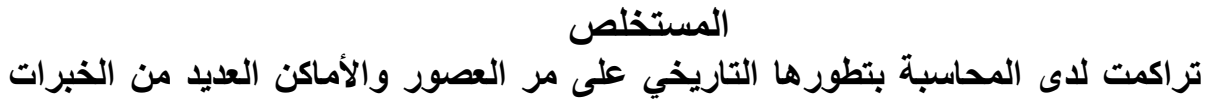

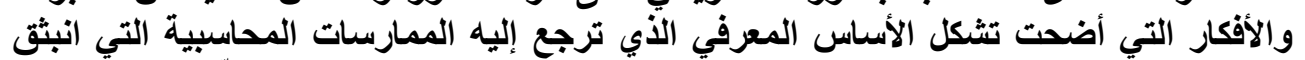

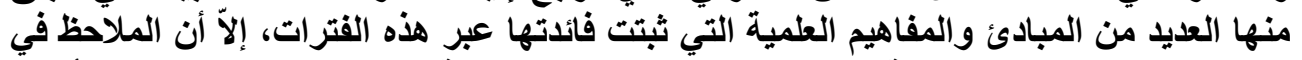

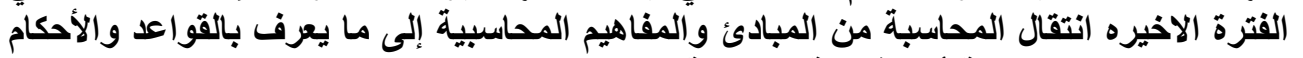

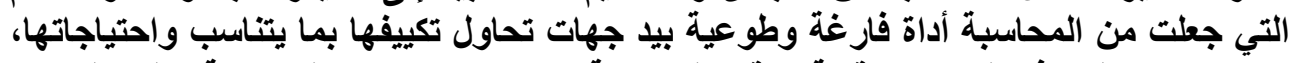

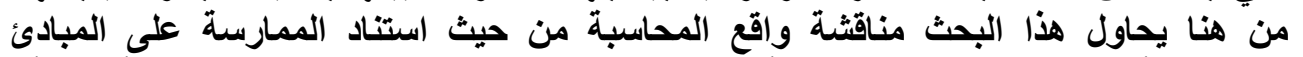

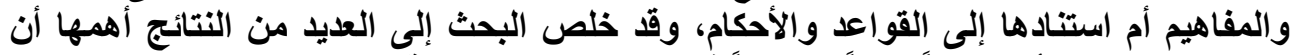
المبادئ والمفاهيم أدت دوراً مهماً وإيجابياً في تدعيم علم والما المحاسبة.

الكلمات المفتاحية:

\title{
Is The Accounting Principles And Concepts Or Rules And Regulations An International Perspective
}

\author{
Qasim M. Al-Hubaity (PhD) \\ Professor \\ Department of Accountancy \\ University of Mosul
}

\author{
Mahir A. Al-Shaman (PhD) \\ Lecturer \\ Department of Accountancy \\ University of Mosul
}

\begin{abstract}
Accounting in historical development over the ages and places has accumulated many experiences and ideas that have became a knowledge base. The accounting practices have related and the some principles and concepts have also emerged. The advantages of these


items have been proved. Recently, the ideas and principles have transferred into rules and bases that made the accounting situation as a vein tool by aspects to adapt with it suitably. This research tries to discuss the accounting according to rules and bases. The research concluded to a group of positive results.

\section{Keywords:}

Principles Accounting Concepts, Accounting Rules, Provisions

المقدمة

قد يتساءل البعض سواء كان من المحاسبين أو غير المحاسبين هل المحاسبة هي

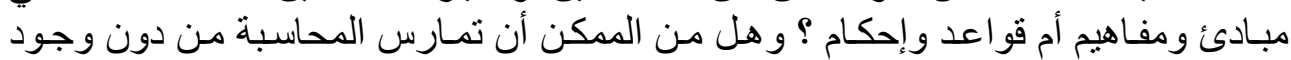

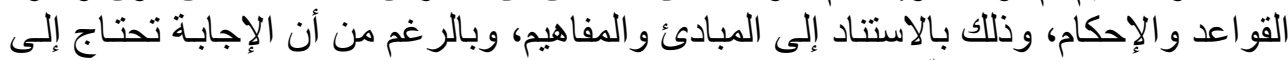

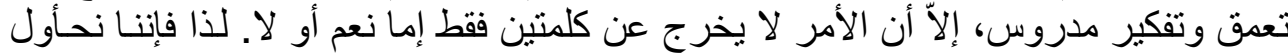

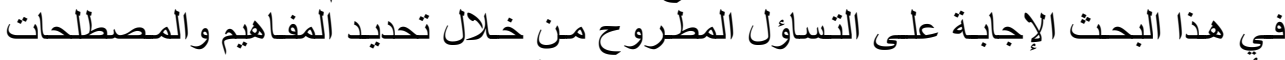

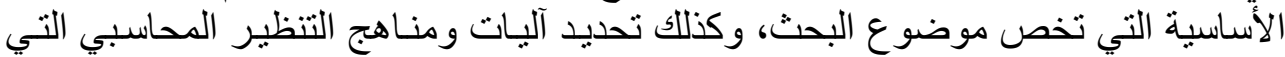

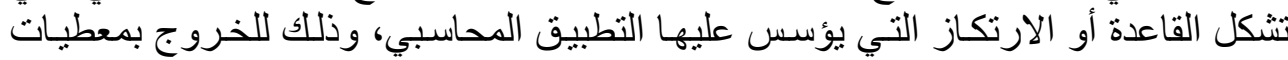
علمية مدروسة وصحيحة عن و اقع الممارسة والتونئ التظير المحاسبي.

مشكلة البحث

تتحدد مشكلة البحث الأساسية بالتساؤل هل المحاسبة تتشكل مـن مجموعـة مبـادئ ومفاهيم أم من مجموعة قو اعد وأحكام؟ و على هذا الأسـاس يمكن اشتقاق المشاكل البحثية

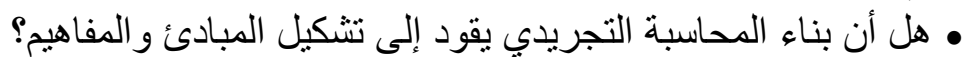
• أم أن بناء المحاسبة بالاستناد إلى الو اقع الفعلي يقود إلى قو اعد و أحكام؟

$$
\begin{aligned}
& \text { هدف البحث } \\
& \text { هنالك العديد من الأهداف يسعى البحث إلى تحقيقها يمكن تحديدها بالآتي: }
\end{aligned}
$$

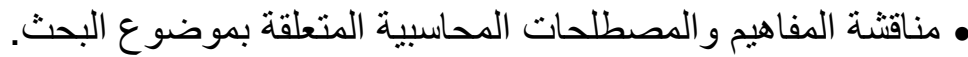

$$
\begin{aligned}
& \text { • مدى الحاجة إلى المبادئ و المفاهيم المحاسبية. } \\
& \text { • مدى الحاجة إلى القو اعد و الأحكام المحاسبية. }
\end{aligned}
$$

تأني أهمية البحث من الإجابة على التساؤل المطروح في مشكلة البحث الذي يتمثنل

$$
\text { أهمية البحث }
$$

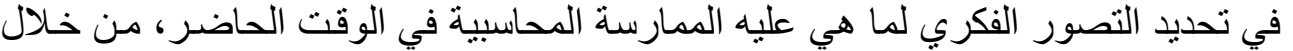

$$
\text { المناقثات الفكرية التي سيتم التطرق إليها في منن البحث. }
$$

يينى البحث على فرضية مفادهـا أن التجرد في المحاسبة سوف يؤدي التهي إلى تشكيل

$$
\text { فرضية البحث }
$$

مجمو عة المبادئ و المفاهيم المحاسبية الضرورية التي تؤسس لبناء نظرية المحاسبة. 


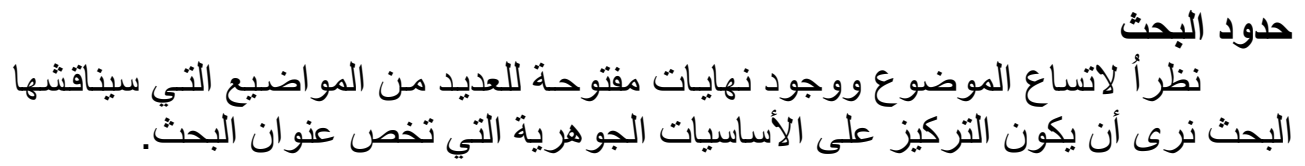

لأجل تحقيق هدف البحث واختبار فرضيته والإجابة على التساؤل المطروح في متن مئن

منهج البحث

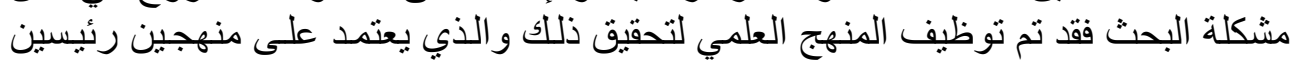

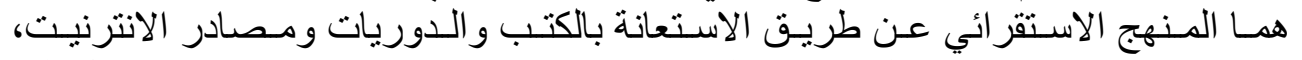

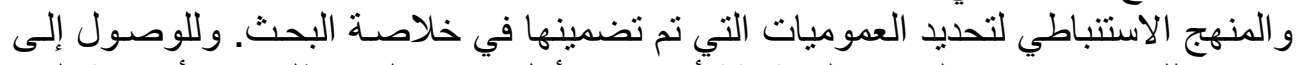

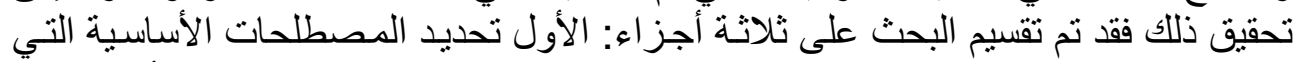

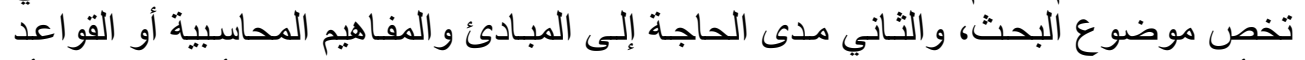

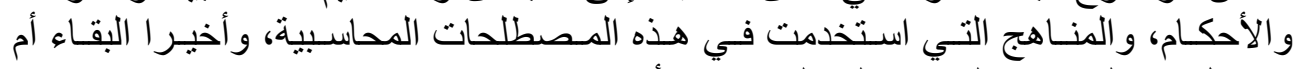
الانتقال من البادئ و الدفأهيم إلى القو اعد والأحكام.

أولاً - المصطلحات الأساسية

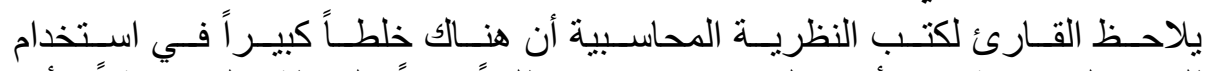

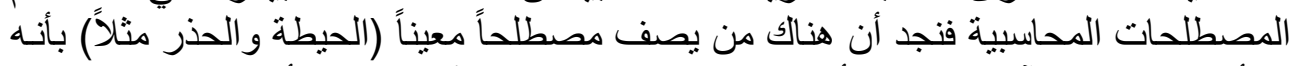

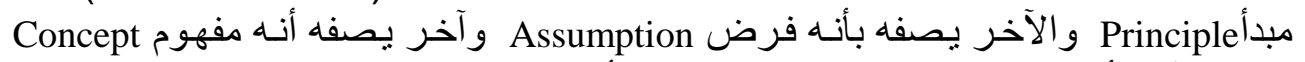

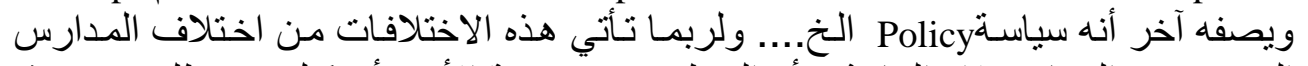

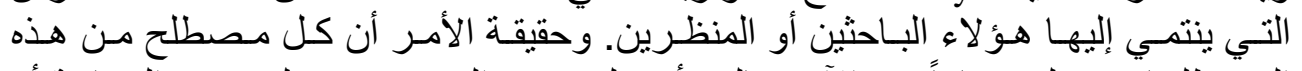

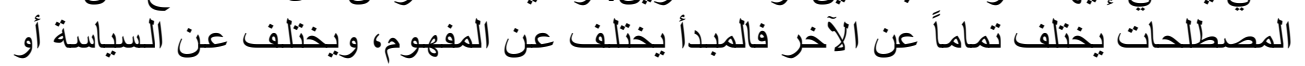

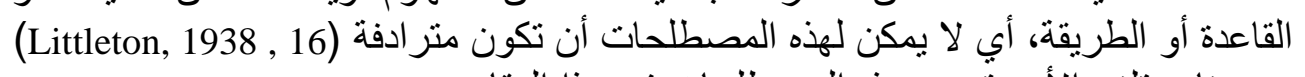

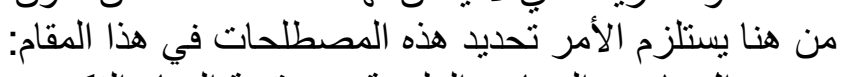

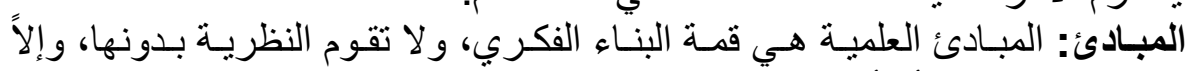

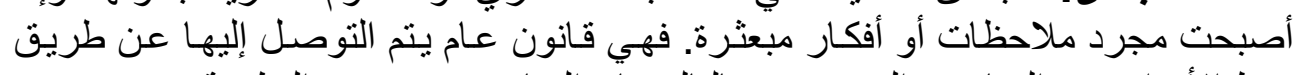

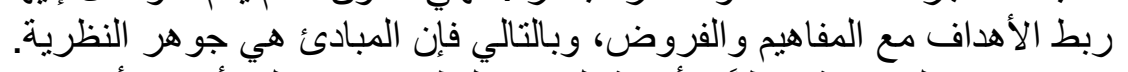

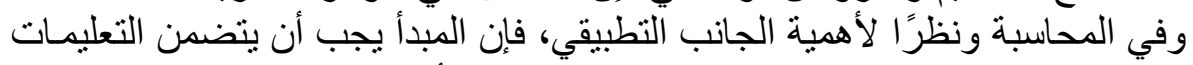

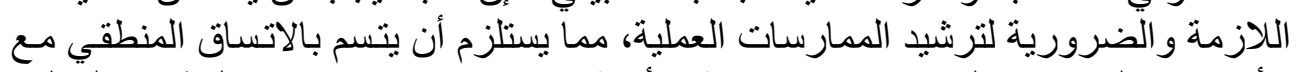

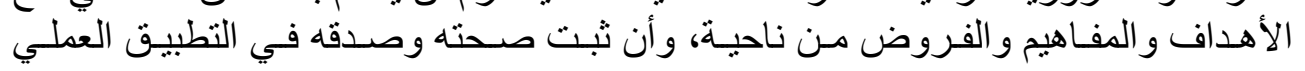

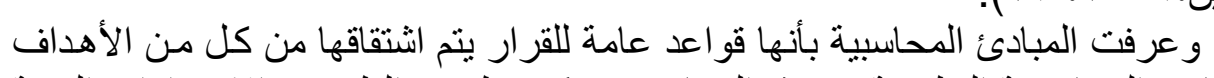

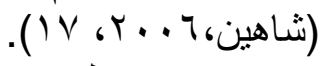

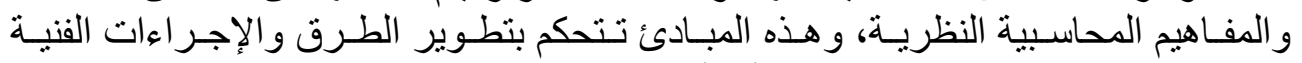

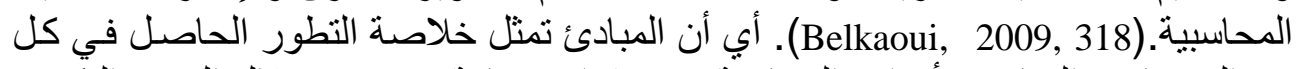

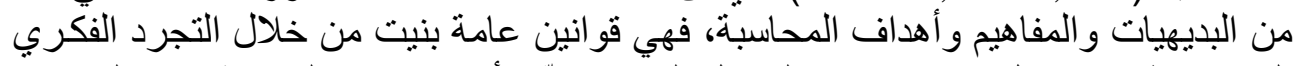

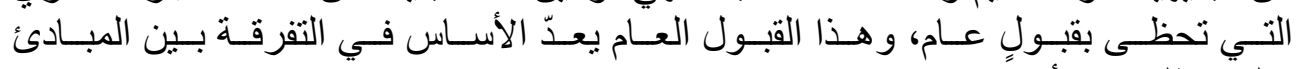
و المصطلحات الأخرى.

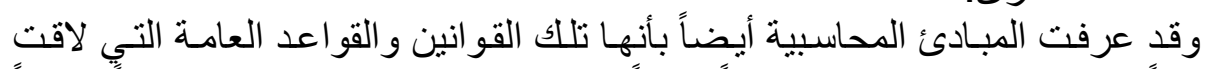

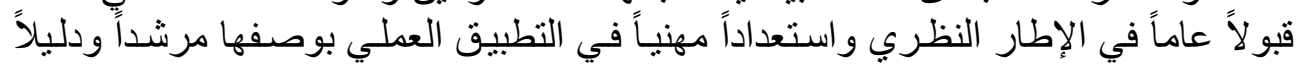


للعمـل يلجـأ إليـه المحاسبون في مواجهة المشناكل المحاسبية وتقديم الحلول لهـا (النقبـ،

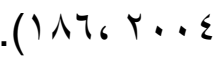

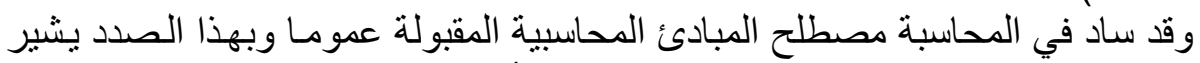

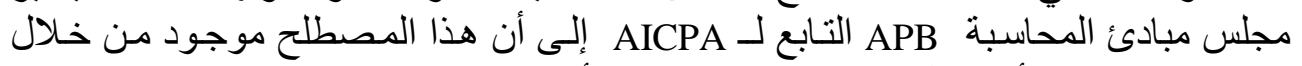

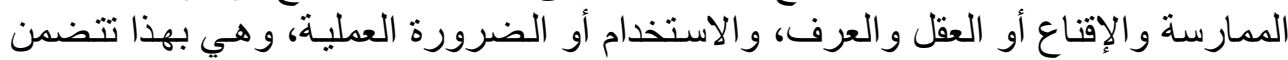

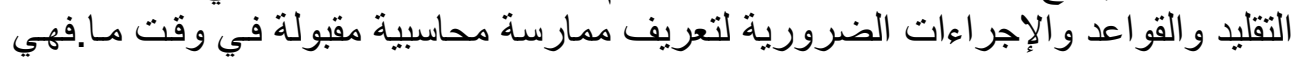

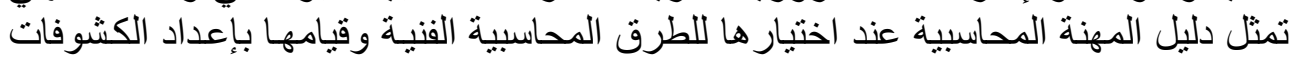

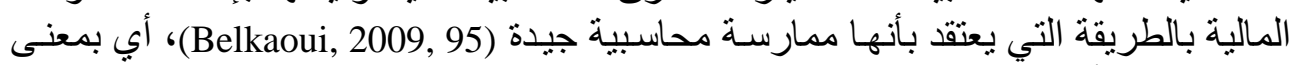

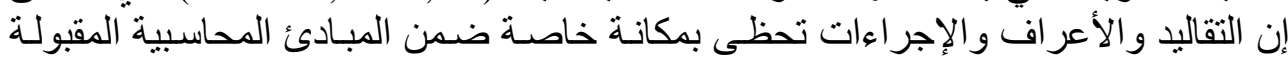

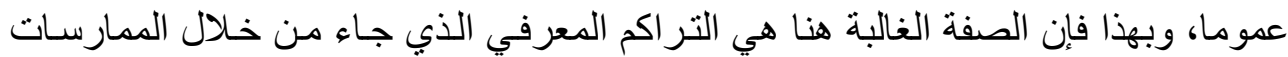

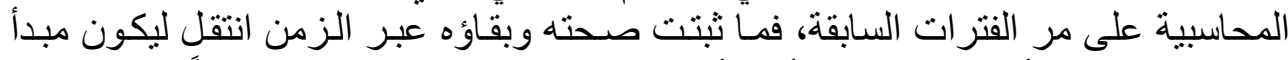

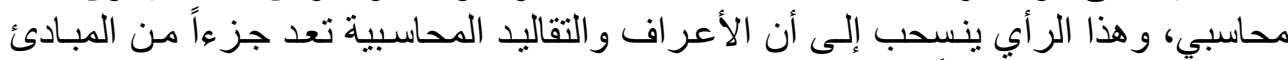
المحاسبية المقبولة ولة عموماً.

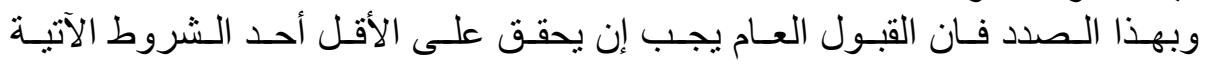

:(Belkaoui, 2009, 96)

الاستخدام: بمعنى إن الطريقة هي قيد الاستخدام فعلاً.

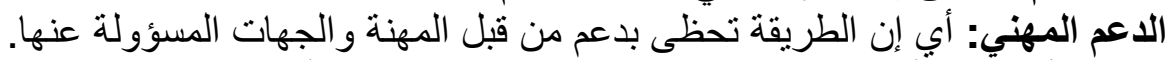

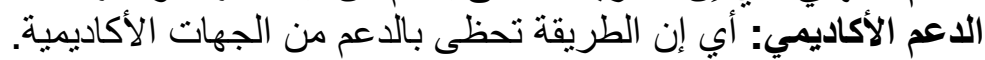

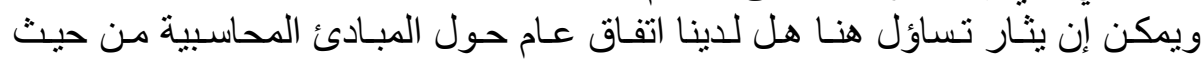

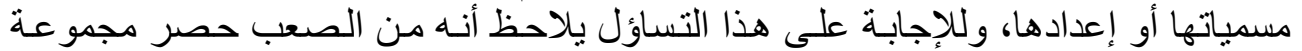

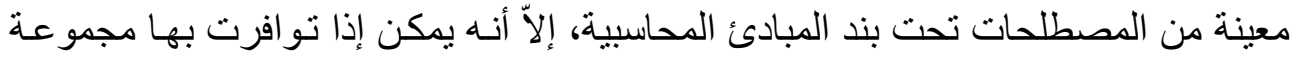
من الخصائص إن تعد من المبادئ المحاسبية:

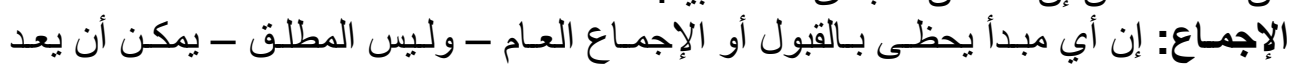

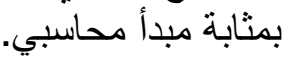
القدرة على التفسير: أي أن تكون لها القدرة على تفسير الممارسة المحاسبية السائدة.

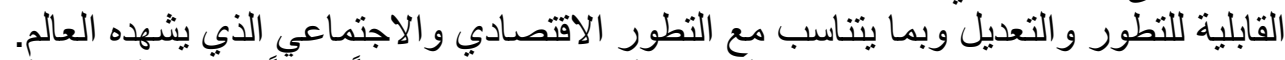

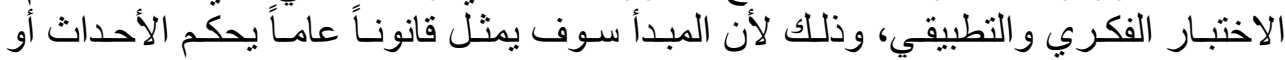

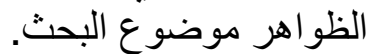

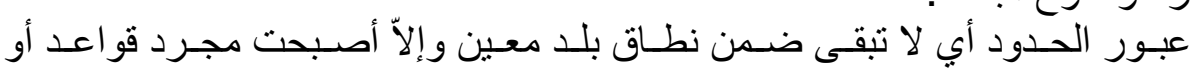
تعليمات محلية. التجريد: ويقصد بـهـ عدم التدخل السياسي الذي قد يمـارس على إجر اء أو حدث معين أو

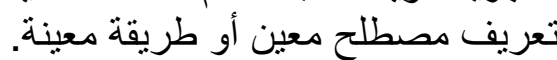

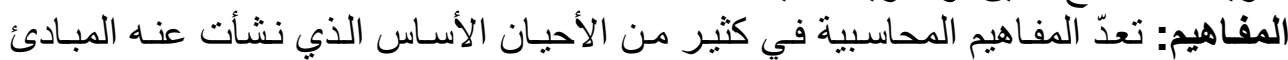

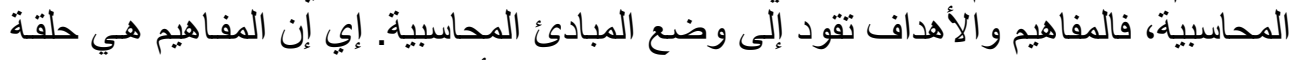

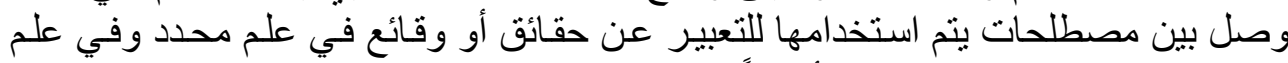

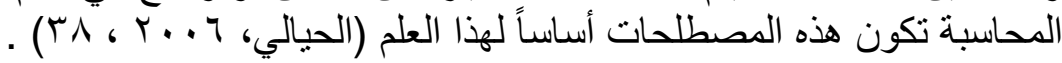




\section{الحبيطي والشمام[rry}

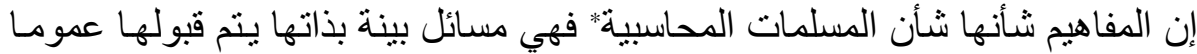

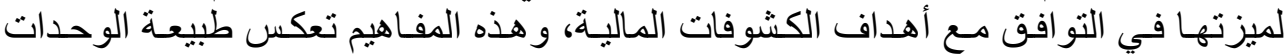

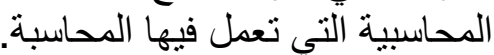
وبهذا فإن المفاهيم قد عرفت الفيات بأنها عبارة عن مجموعة متجانسة من الأفكار الأساسية

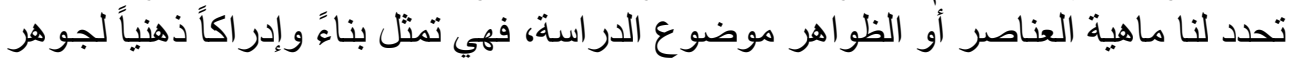

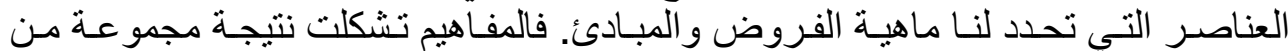

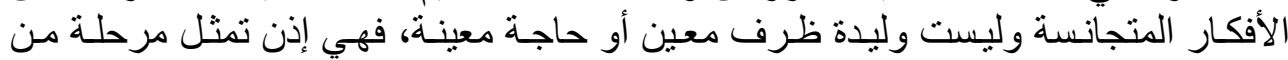

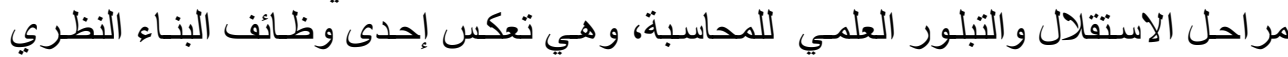
للمحاسبة، ومجمو عها يشكل الإطار ألمفاهيمي الذي تبنى منه النظرية الإنية المحاسبية.

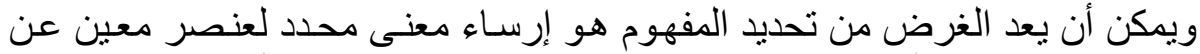

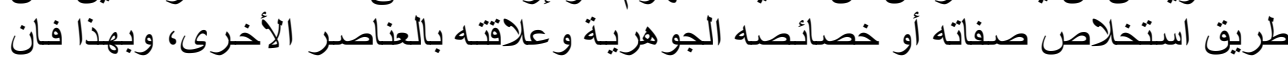

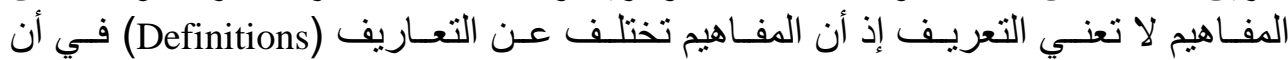

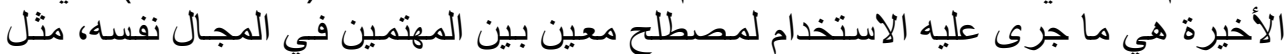

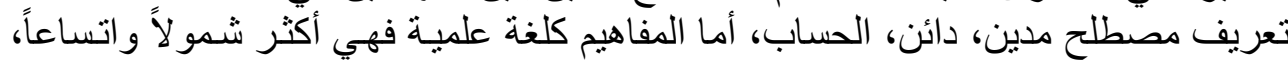

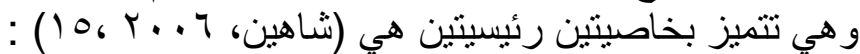

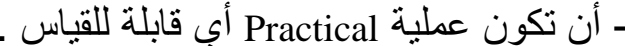
ـ أن تكون إجر ائية Operational بمعنى أن يشتمل المفهوم على مضنمون يوضتح إجراءات

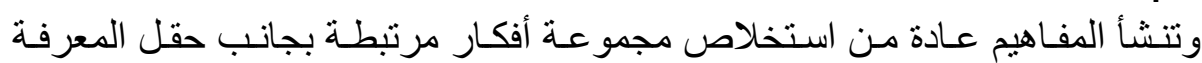

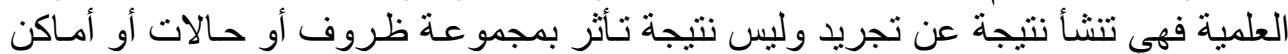

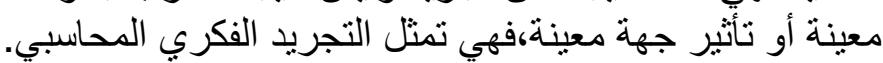

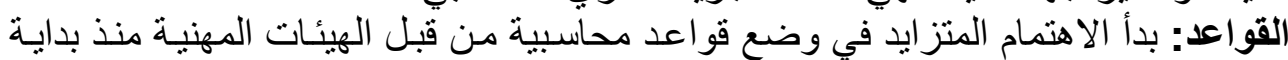

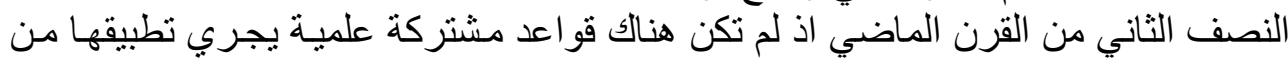

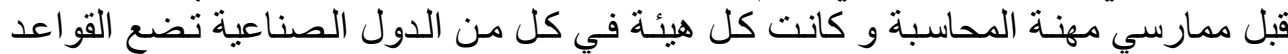

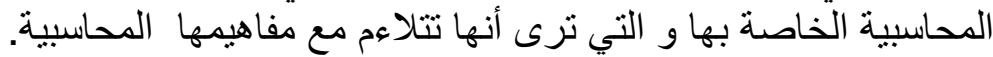

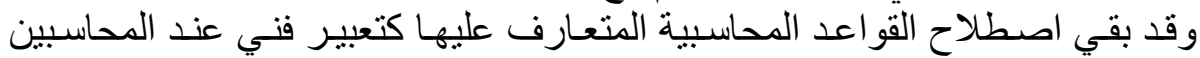
مفهوما يشمل كل ما هو متفق عليه في علم المحاسبة ومقبول من الشركات ولف و المؤسسات

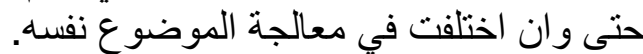

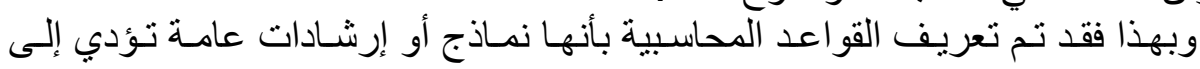

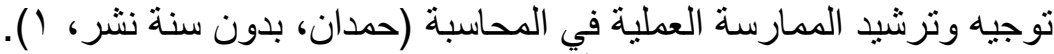

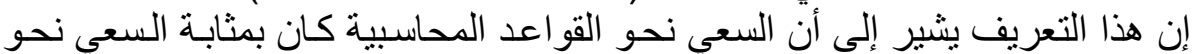

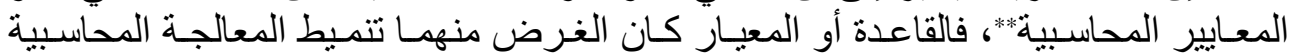

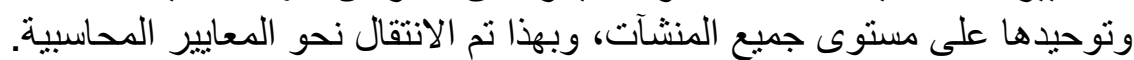

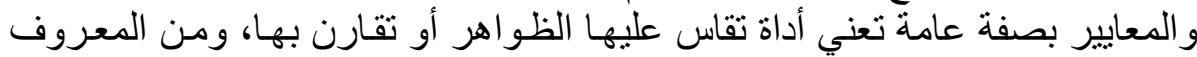

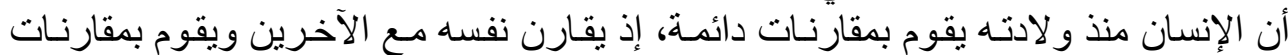

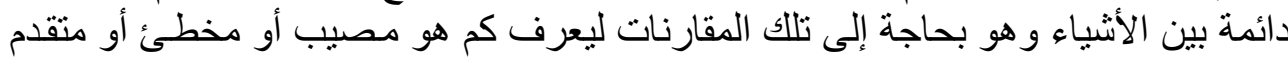

* المسلمة هي حقيقة قائمة بذاتها و لا بحتاج إلى التحقق منها.

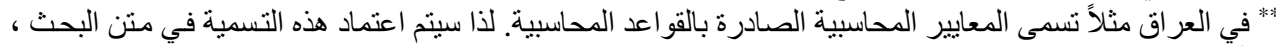
و أينما ورد معنى قاعدة فإنه نعني به معيار . 


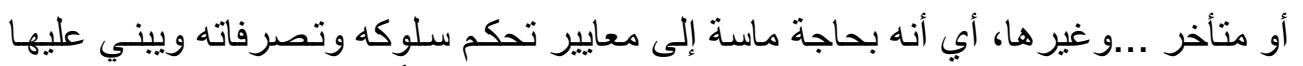

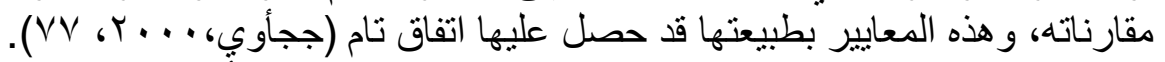

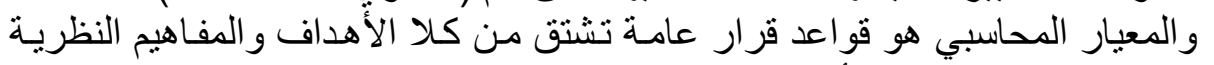

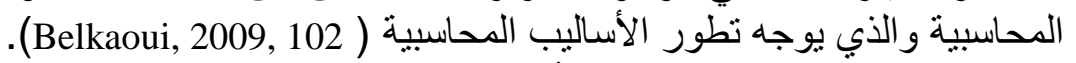

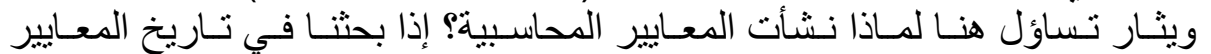

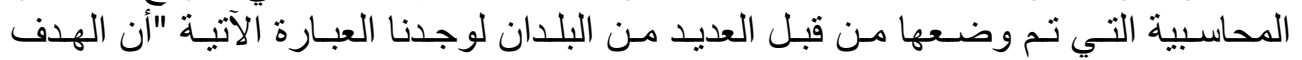

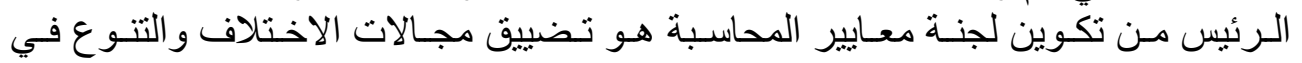

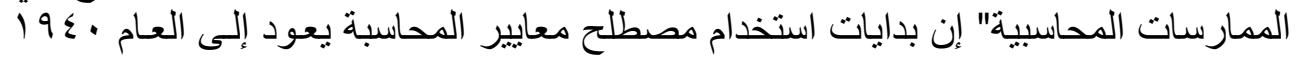

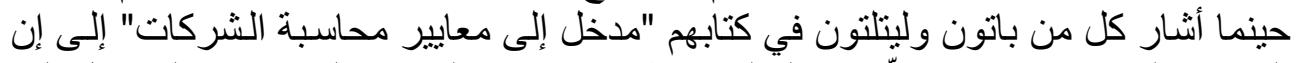

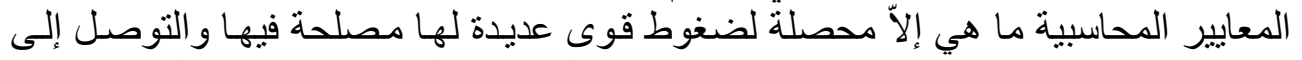

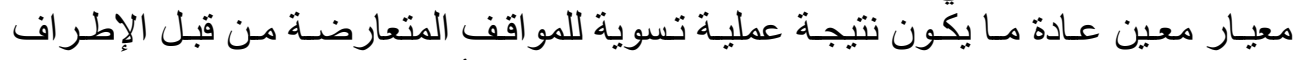

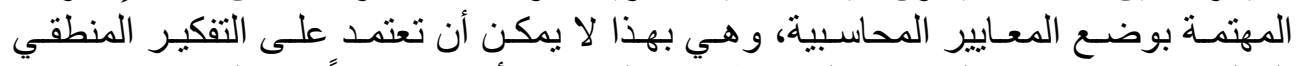

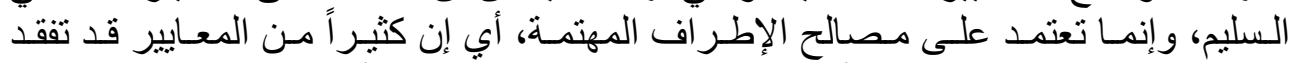

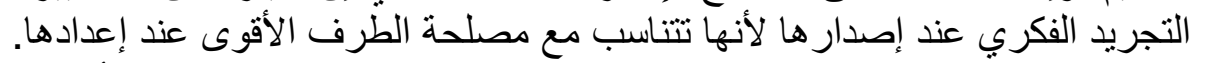

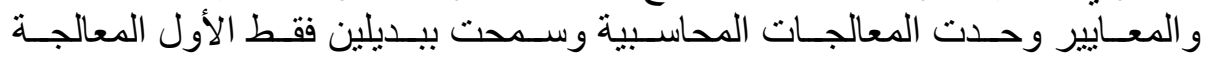

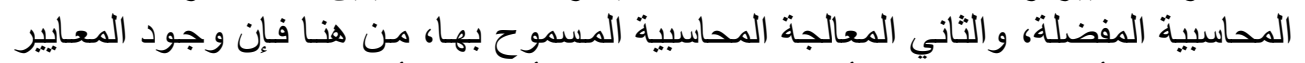

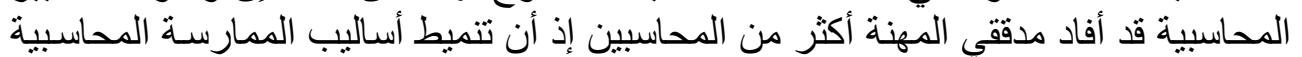

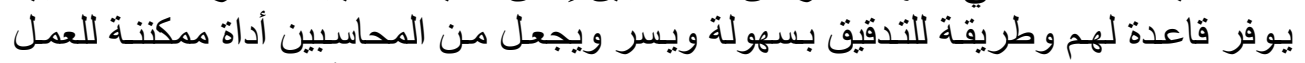

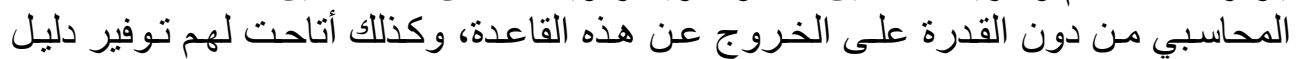

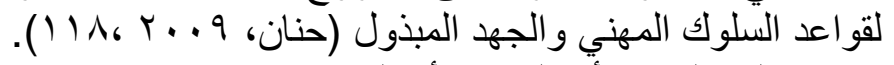

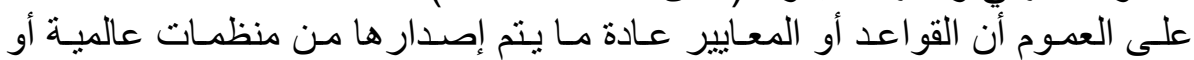

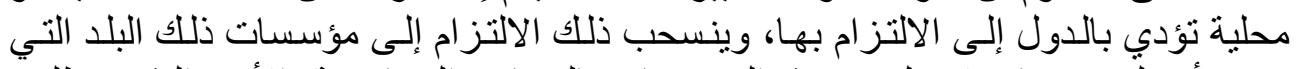

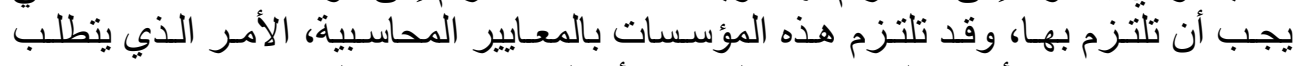

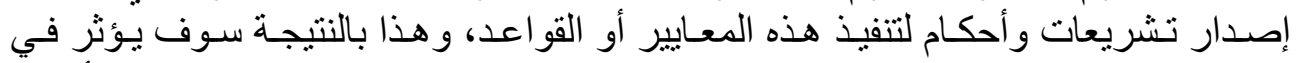

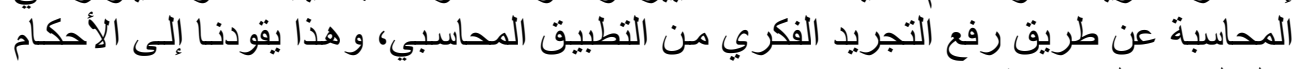

و التعليمات المحاسبية. الأحكام: تشكل الأحكام المحاسبية مجمو عة التعليمات أو القو انين المحلية التي تصدر ها جهة

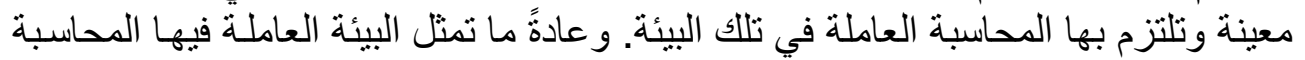

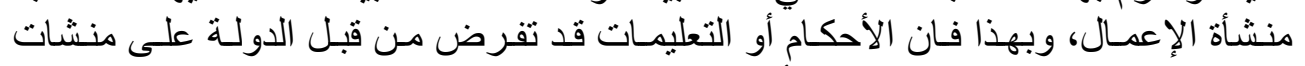

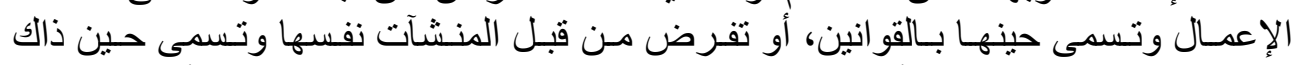

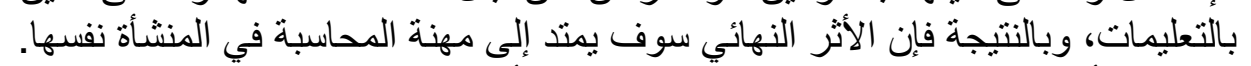

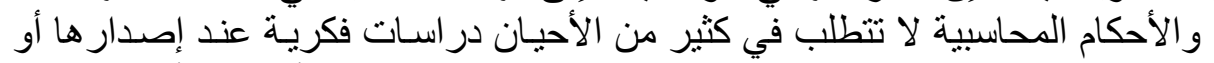

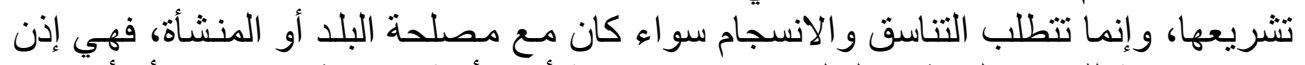

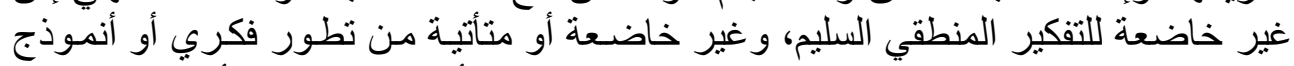

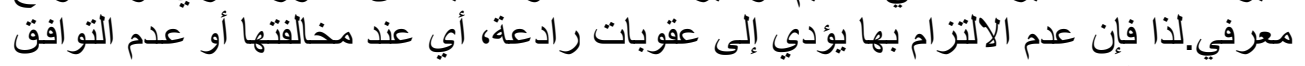

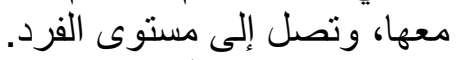

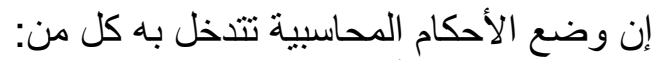

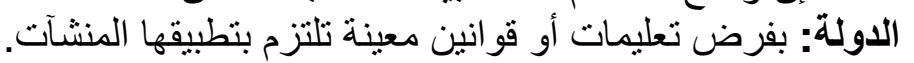




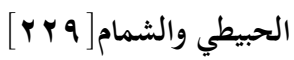

المهنة: وتتمثل بالجهة المنظمة لمهنة المحاسبة، وتتبع قوة الأحكام التي تصدر ها من قوة القو انين التي تسندها قوة القانون.

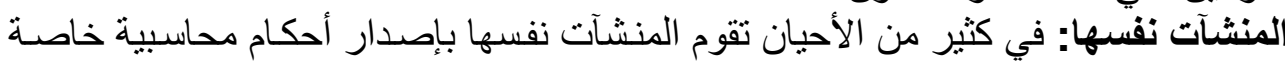
بها تلتزم بها أقسام المحاسبة.

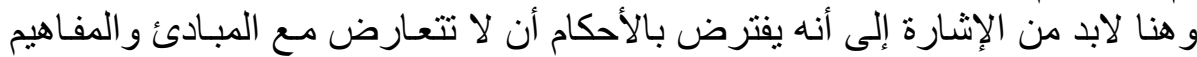

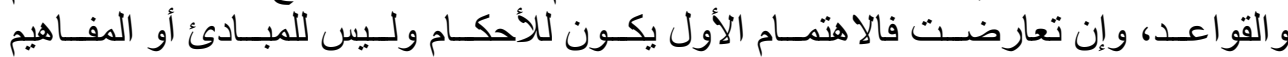

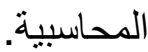

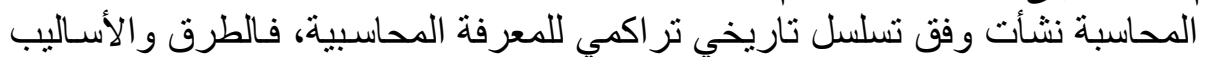

$$
\text { متى تم اللجوء إلى القواعد والأحكام: }
$$

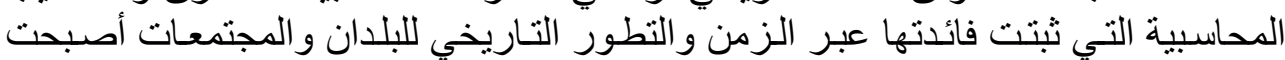

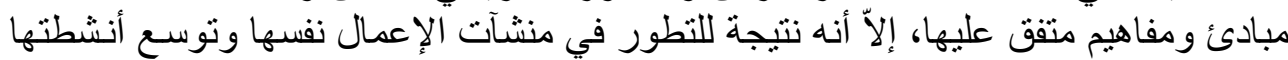

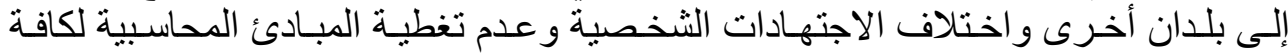

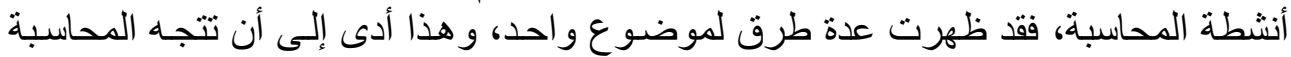

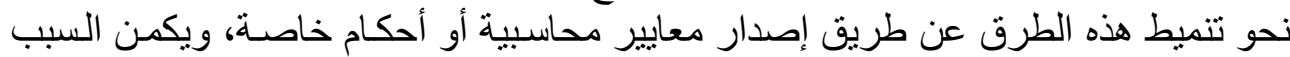
الرئيس ور اء ذلك في أن المحاسبة كانت مرتكزة على الفن أكثر منه على العلم.

ثاتياً- الحاجة إلى المبادئ والمفاهيم أم إلى القواعد والأحكام

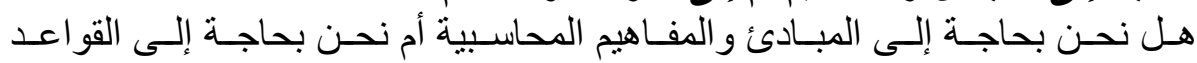

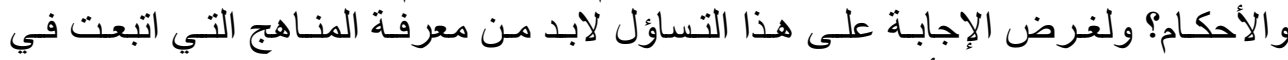

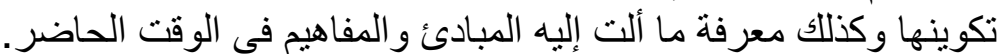

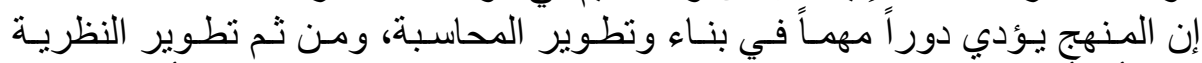

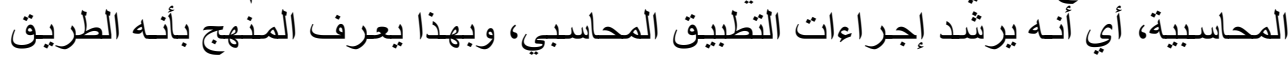

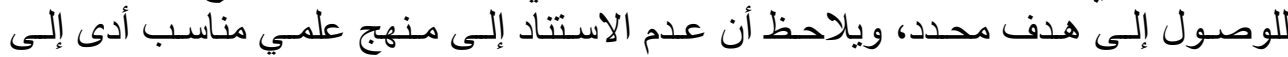
الارتباك في علم المحاسبة.

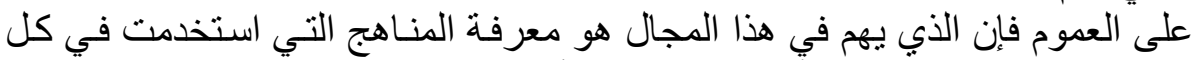
من المبادئ و المفاهيم و القو أعد و الأحكام و هي كما يأني:

1 - مناهج تكوين المبادئ والمفاهيم المحاسبية

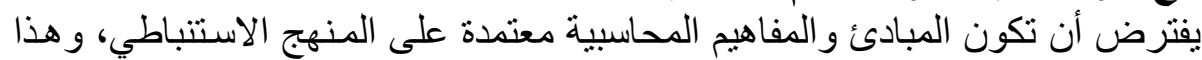

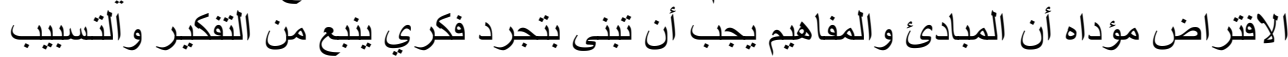

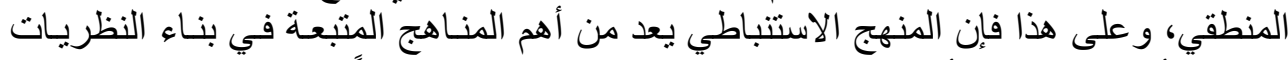

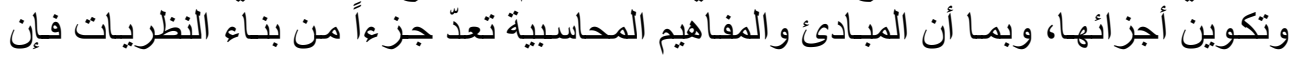
الاستتباط ضروري في عملية التكوين الفكري.

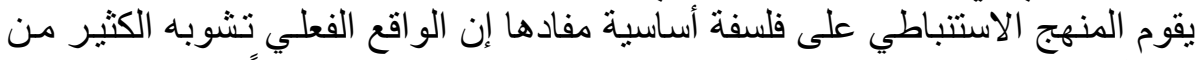

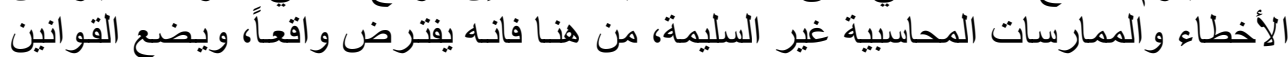

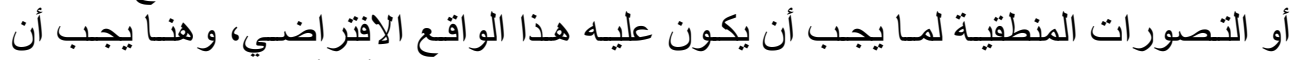

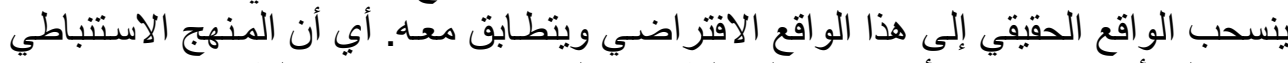

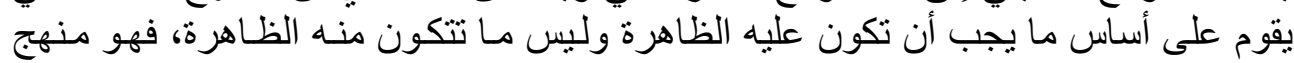


معباري يقاس عليه، و هذا المنهج قو امه العقل و التفكير المنطقي ويبتعد عن التجريب، و هذه

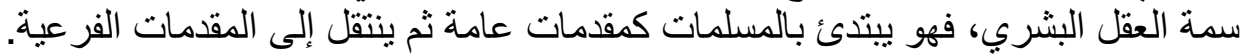

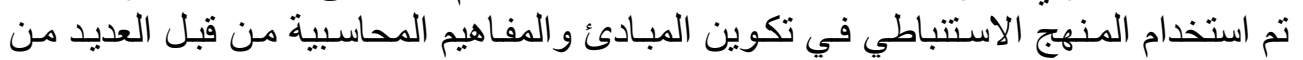
الجهات العلمية والمهنية وكان من أبرز تلك الجهات":

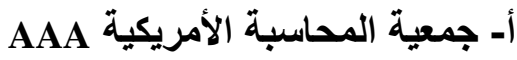

أسهمت هذه الجمعية في تحديد المبادئ المحاسبية من خلال النشرة البحثية الصادرة

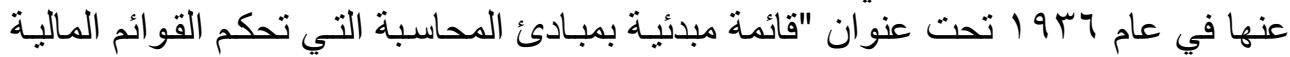

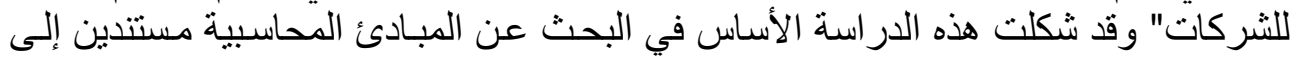

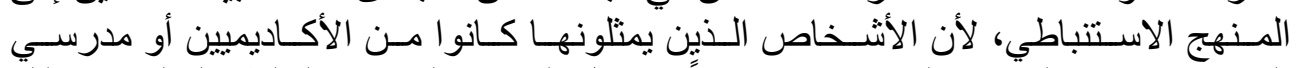

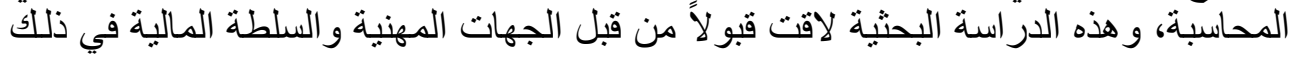

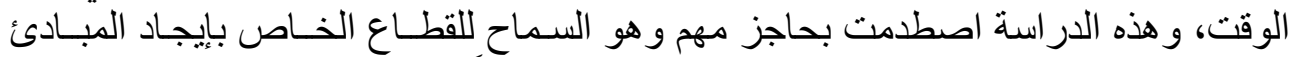

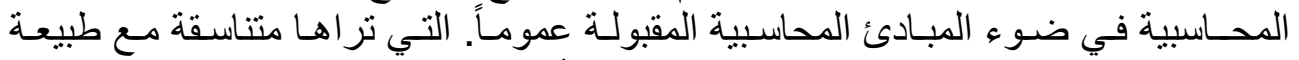

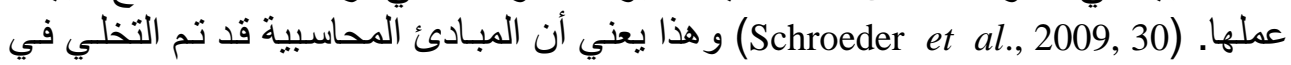
مجال تكوينها عن التفكير المنطقي.

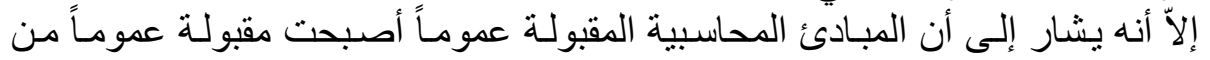

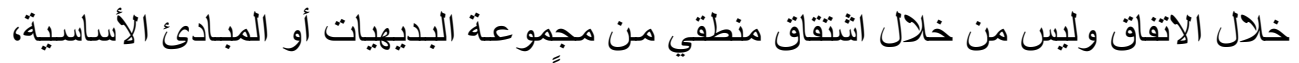

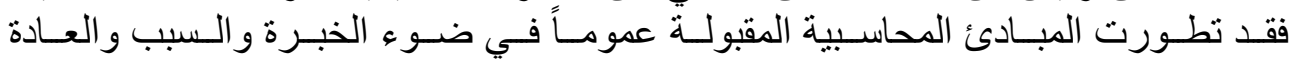

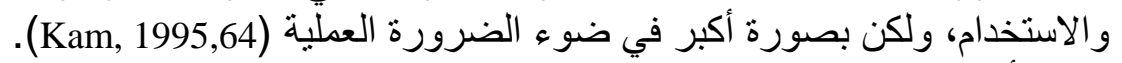

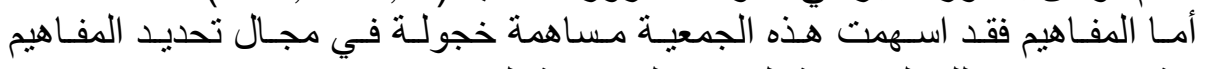

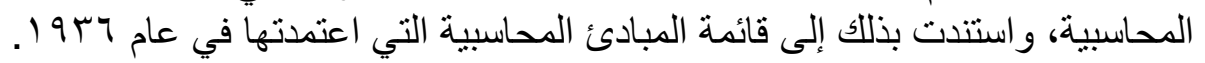

\section{بـ المعهز الأمريكي للمحاسبين القانونين AICPA}

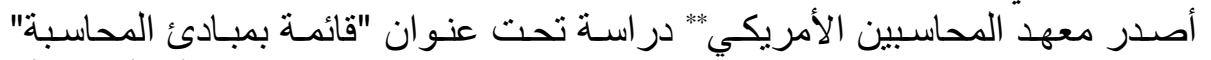

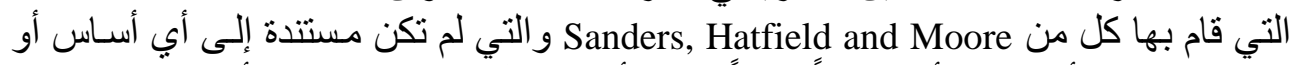

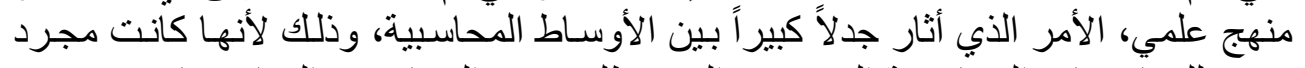

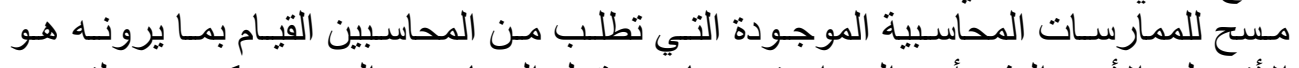

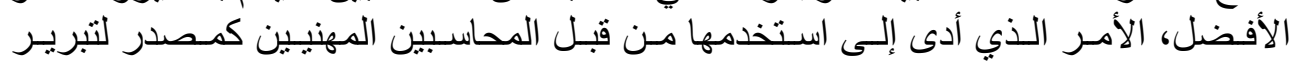

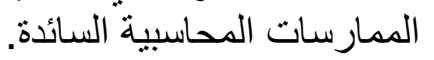
وقد شكل AICPA العديد من اللجان التي كان لهانتانثير كبير في تحديد المبادئ

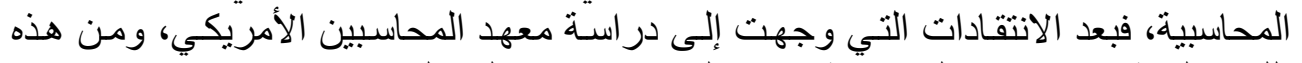

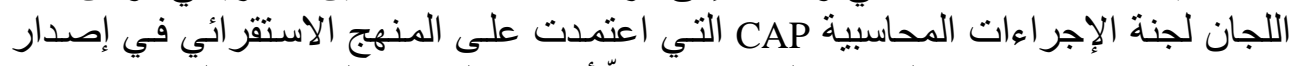

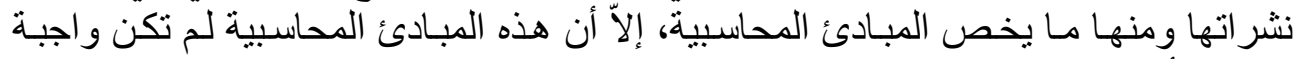
التطبيق أو إجبارية، ولكنها حصلت على سلطنها من القبول العام فقط.

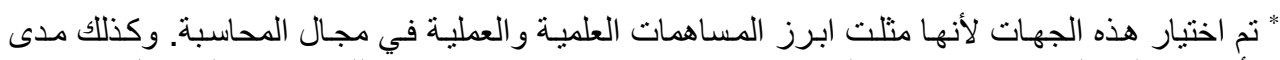

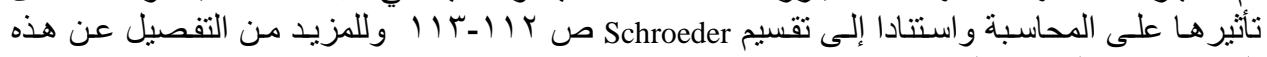

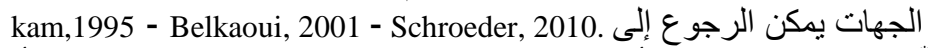

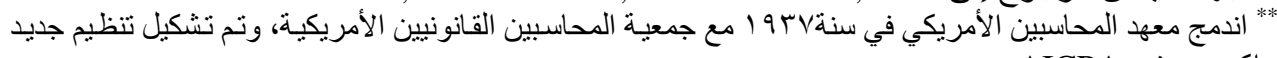




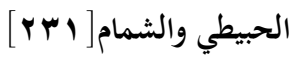

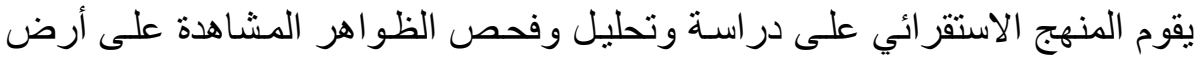

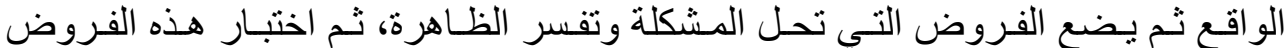

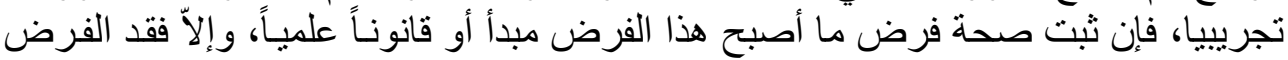

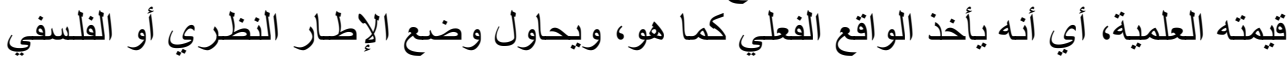

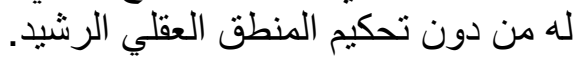

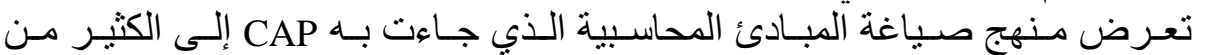

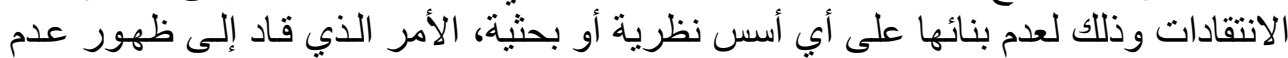

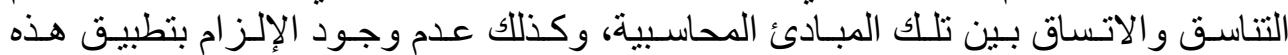

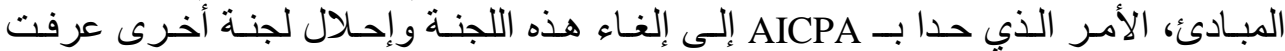

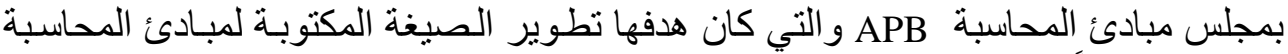

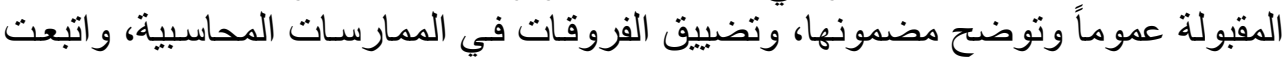

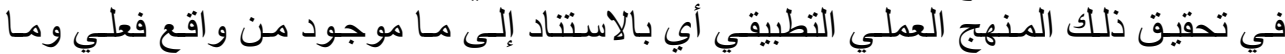
تتكون منه الممارسة المحاسبية (Schroeder et al., 2009,33).

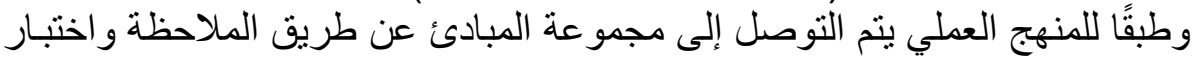

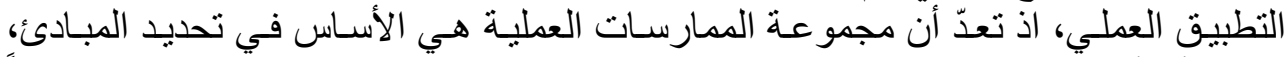

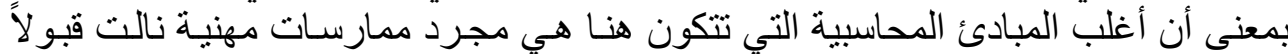

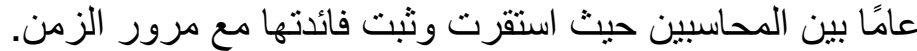

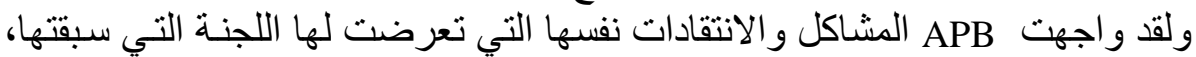

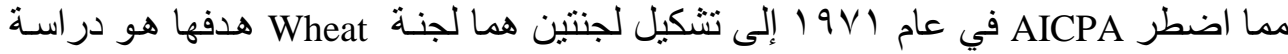
الكيفية التي يجب بها وضع مبادئ المحاسبة المالية، ولجنة Trueblood و هدفها تطوير إطـار مفاهيمي للمحاسبة.

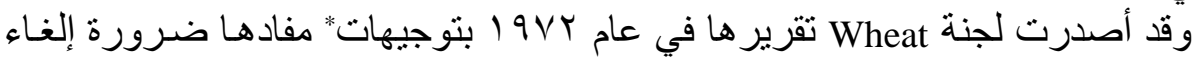

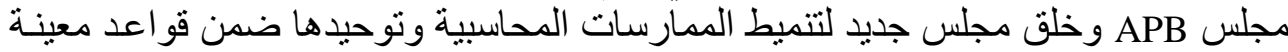

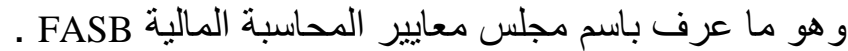

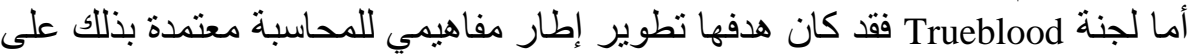

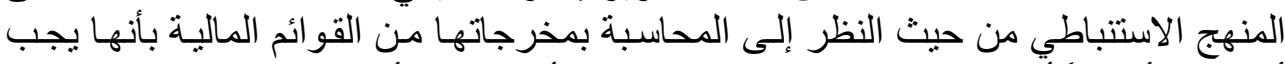

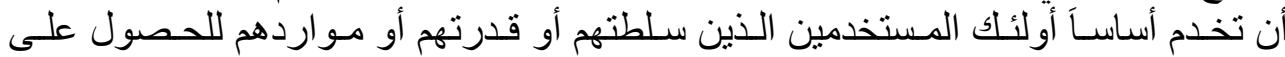

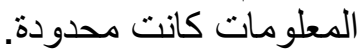

\section{r - r مناهج تكوين القواعد والأحكام المحاسبية}

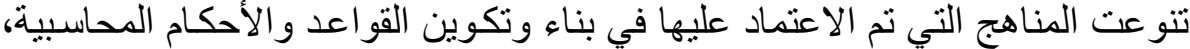

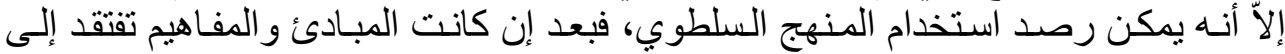
الإلز ام بتطبيقها من قبل المهنـة أصبحت القو اعد والأحكام تمثل السلطة أو الالتنزام الذي لئي

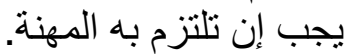

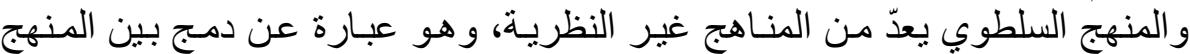

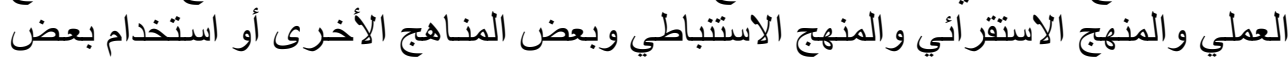


الكنـاهج بحسب الحاجة لها. وسمي بالسلطوي لأنـه، هنـاك سلطة تصدر القو اعد وعلى الجميع تطبيقها.

ويستمد المنهج السلطوي قوته ومادته من السلطة القانونية في البلد، ويمكن أن يلاحظ

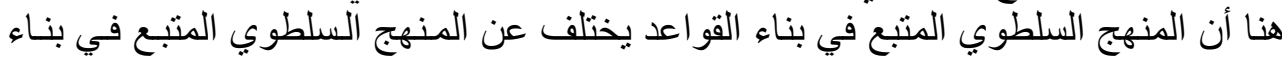

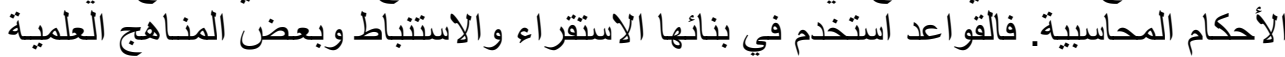

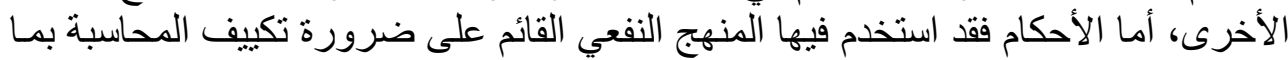

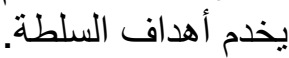

لقد أسهوت العديد من الجهات العلميـة والمهنية في بناء قواعد اعد أو معايير محاسبية

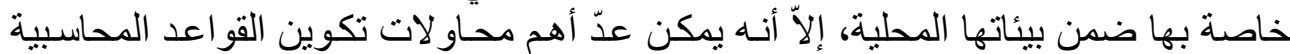

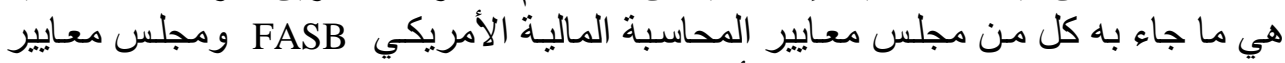
الدحاسبة الدولية IASB و على النحو الأتي:

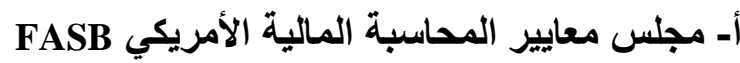

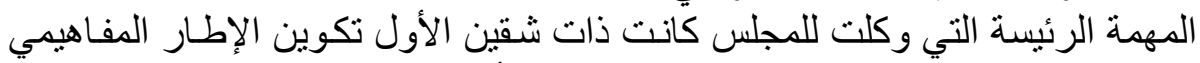

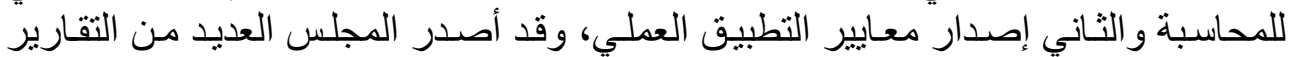

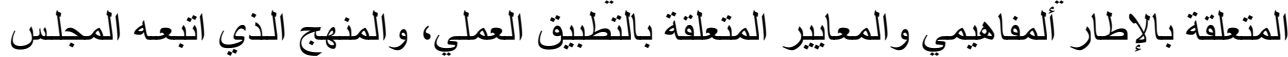

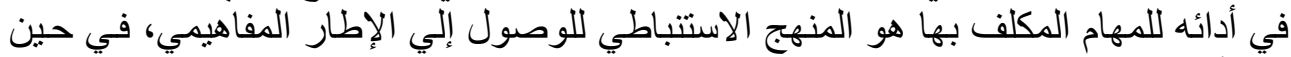

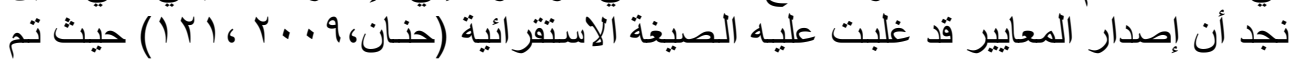

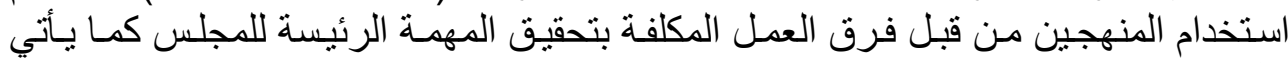

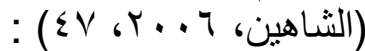
ا ــ إصدار معايير التطبيق العملي باستخدام المنهج الاستقرائي بالآتي: ـ ـ تحديد الموضو عمات التي يلزم إعداد المعايير بشأنها. ـ ـ استقر اء الممارسات التي تستخدم في التطبيق العملي.

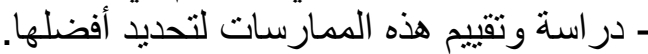
r. تكوين الإطـار المفـاهيمي باستخذام المنهج الاستتباطي من قبل فريق العـل بالمهام

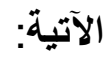
- ت تحديد أهداف التقارير المالية. - ت تحديد قو اعد الاستنتاج التي سوف تستخدم.

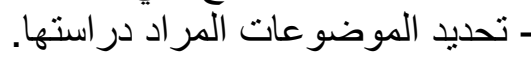
- تطبيق قو اعد الاستتناج للوصول درل إلي المعايير التي تتسق مع الأهداف.

ب- مجلس معايير المحاسبة الدولية IASB

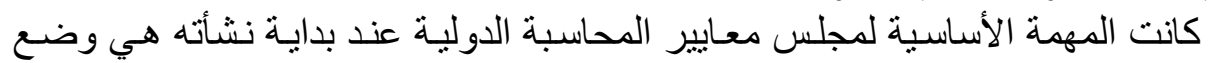

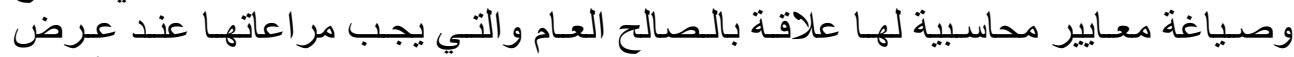

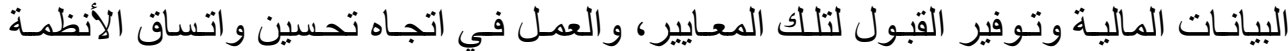

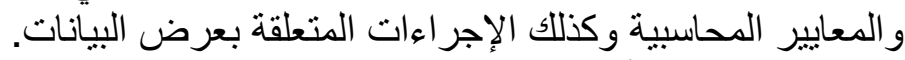

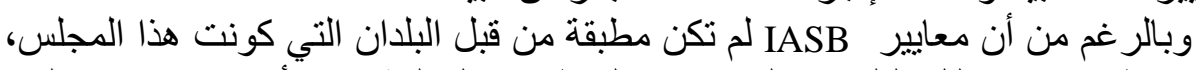

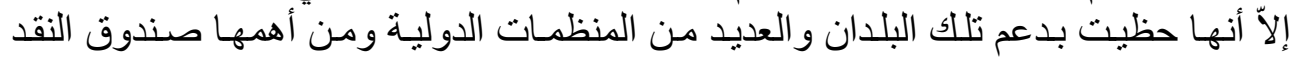




\section{الحبيطي والشمام[rrr]}

الدوليIMF، وقد اعتمد IASB نفس منهاج FASB وذللك لتكوين المعابير المحاسبية، والتي

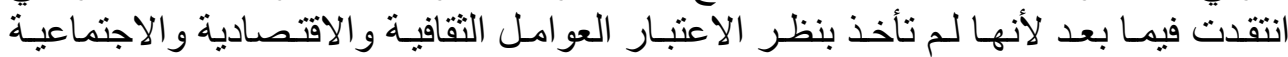
للبلدان التي يفترض بها بها تطبيق تلك المعايير.

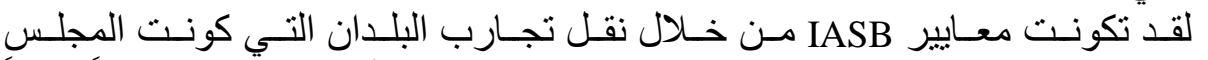

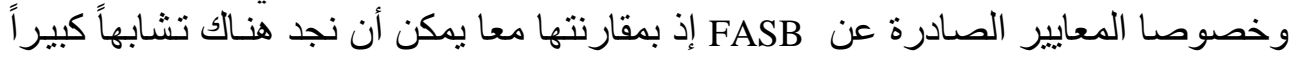

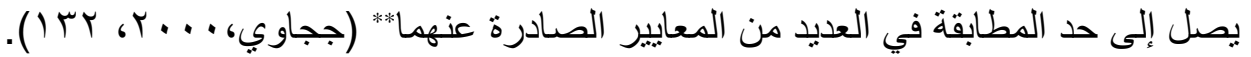

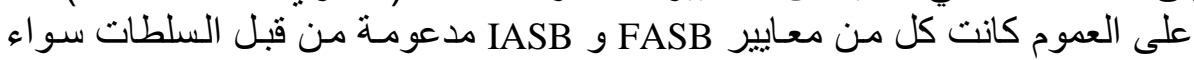

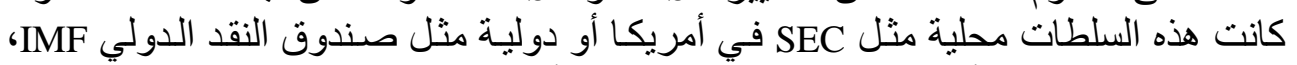

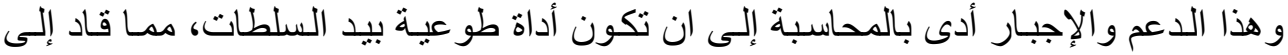
انتفاء الصفة العلمية والمهنية من المحاسبة وجعلها مجردة من الإبداع الفكري الذالة الذي الذي تكونت

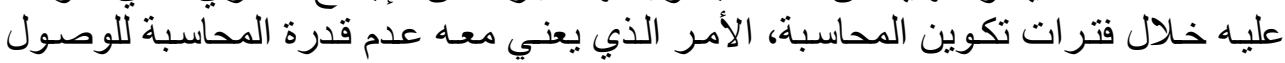

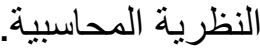

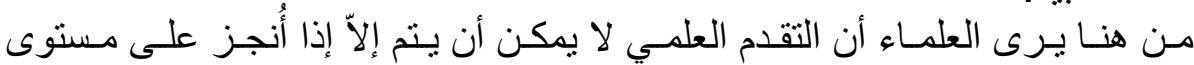

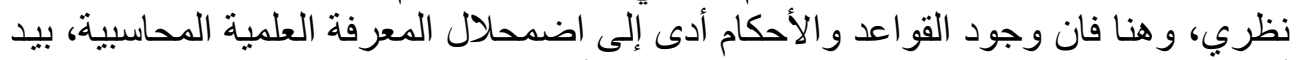

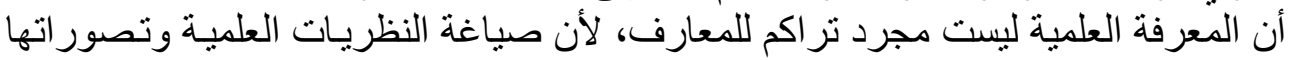

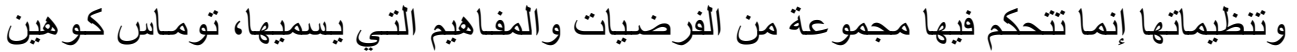
(Thomas Kuhn)

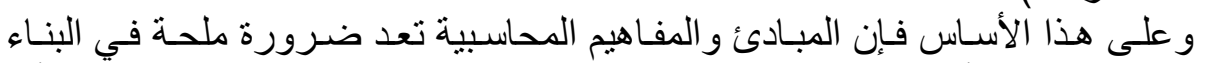

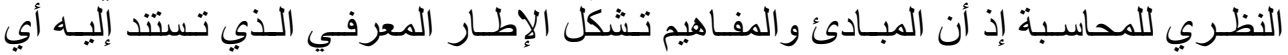

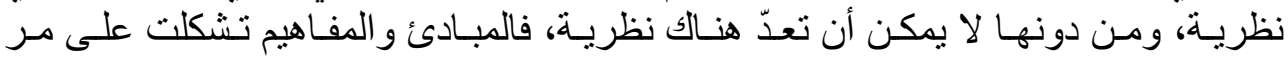

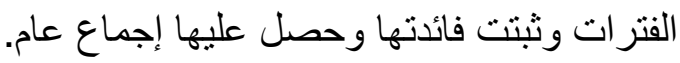

ثالثاًـ أفضلية البقاء أم الاتثقال من المبادئ والمفاهيم إلى القواعد والأحكام

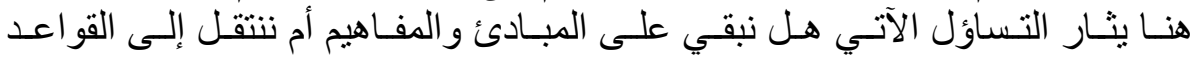

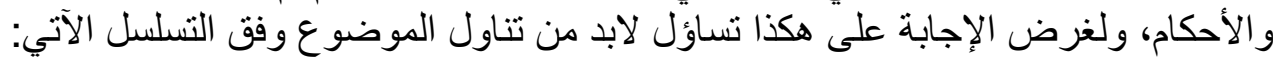

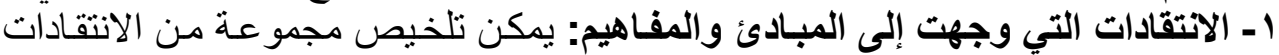

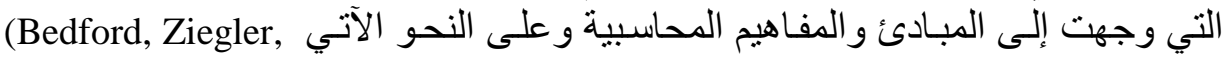
:1975, 435-443) (Zeff,***,1-32)

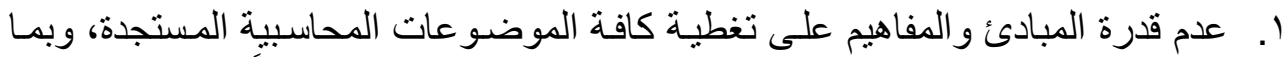

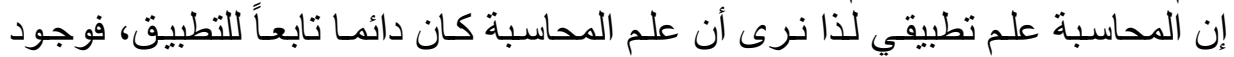

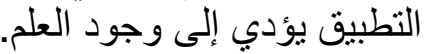

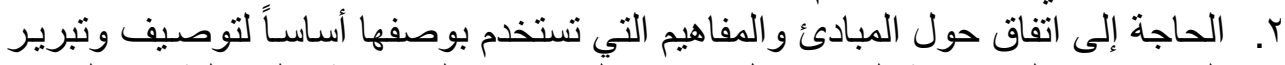

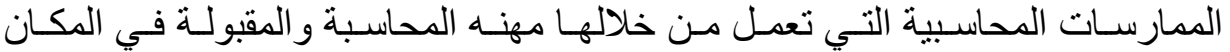
و الزمان، و هذا ما نر اه غير موجود ضمن إطار مجمو عة المبادئ و المفاهيم المحاسبية. 


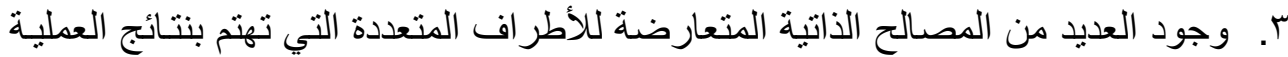

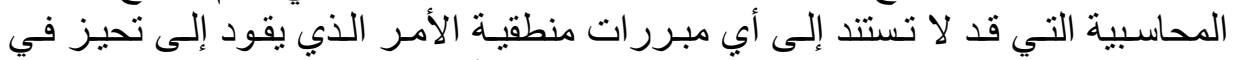

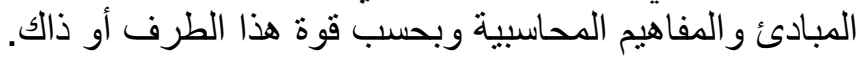

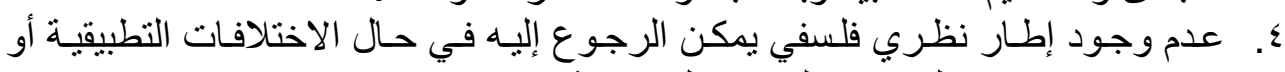
تكوين واستخلاص المبادئ و المفاهيم المحاسبية.

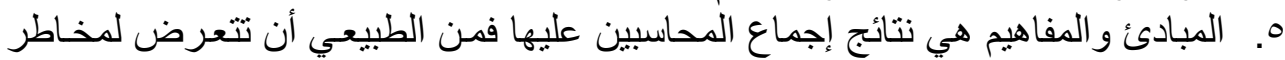

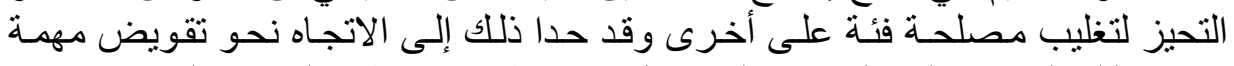

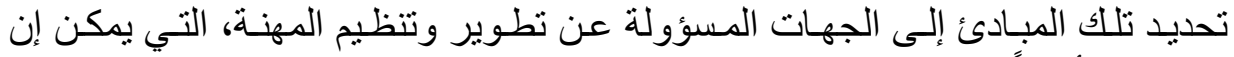
تكون هي أيضاً متحيزة. T. الاختلاف حول عدد وطبيعة المبادئ و المفاهيم المحاسبية و المستخدمة في الممارسـة المحاسبية. V. . الاختلاف الناتج من داخل المبادئ و المفاهيم المحاسبية والتعارض الذي يمكن إن ينشا من داخل هذه المبادئ و المفاهيم.

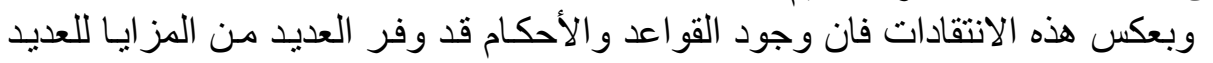

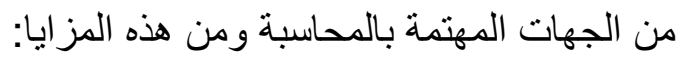

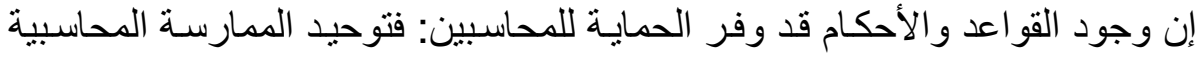

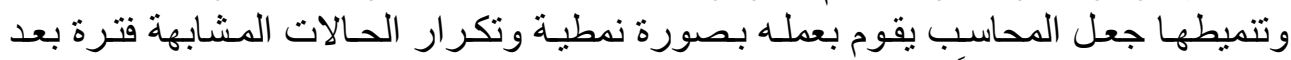

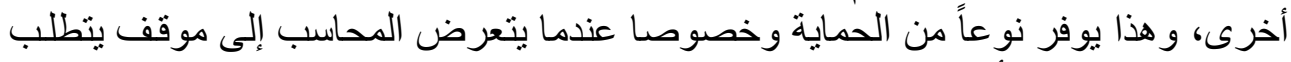

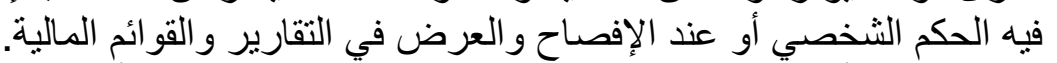

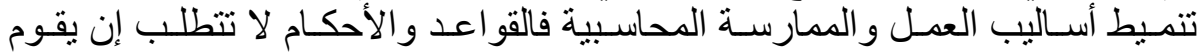

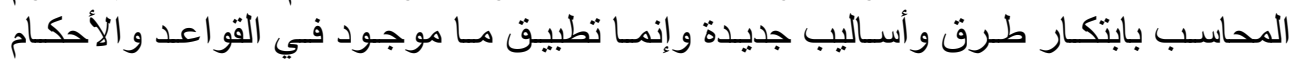
المحاسبية. توحيد أنماط عرض البيانات و المعلومات المحاسبية وعدم تغليب مصلحة فئة على لهى حساب أخرى من الجهات التي لها مصلحة التهر في المنشأنة

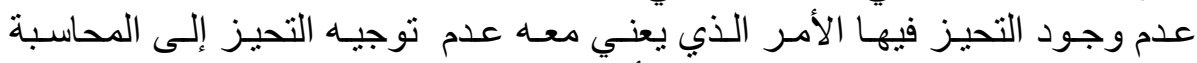

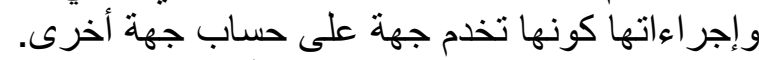

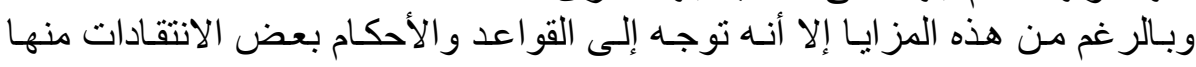

:(Shields, 2010, 1-8)

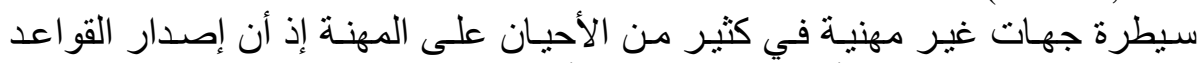

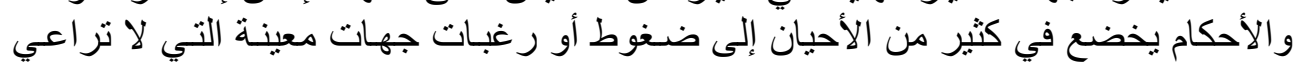

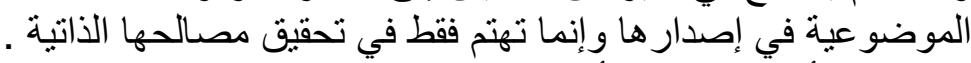

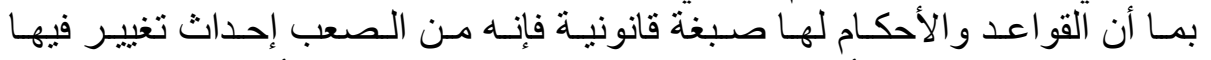

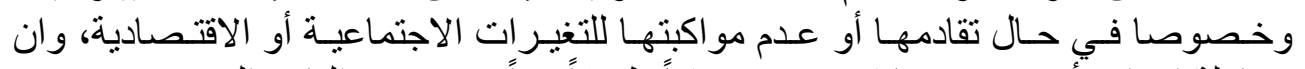

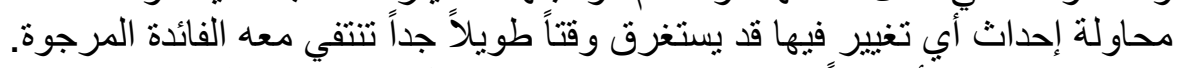

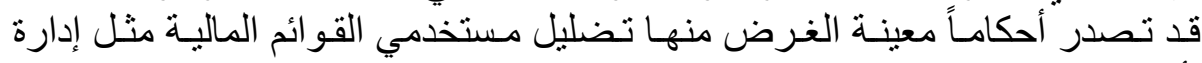

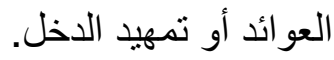

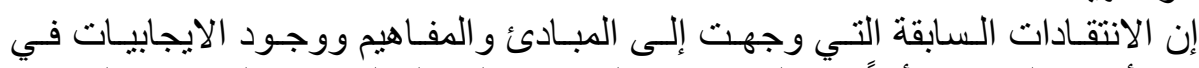

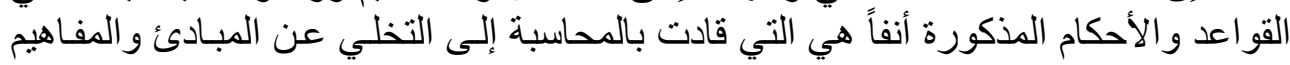




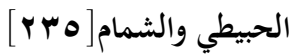

المحاسبية على حساب القو اعد و الأحكام المحاسبية، فضلاً عن بعض العوامل الأخرى التي

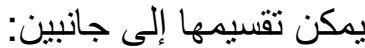
المن داخل المهنة:ويمكن تقسيمها إلى الجهات الآتية:

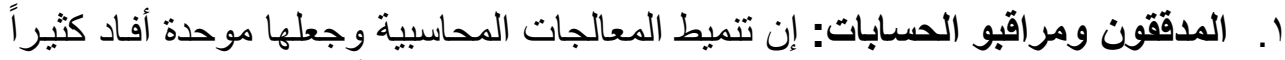

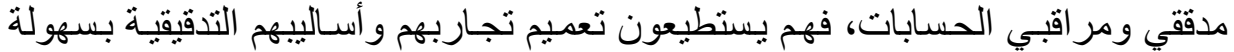

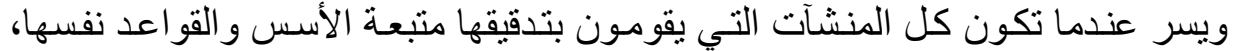

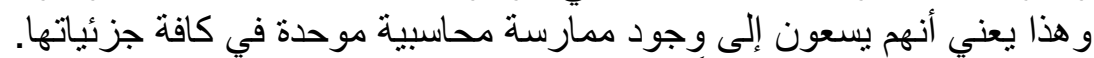

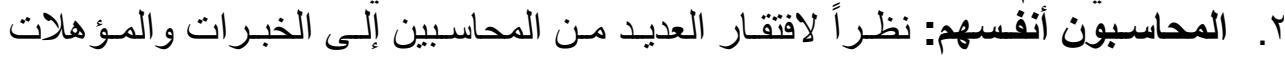

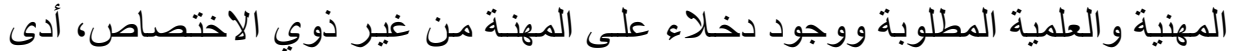

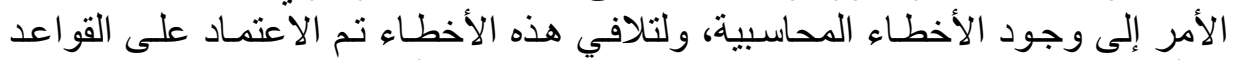

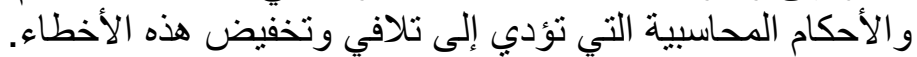

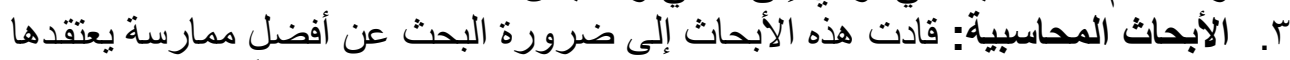

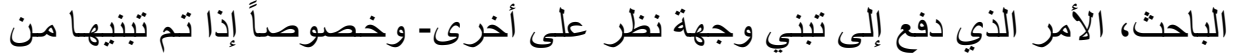

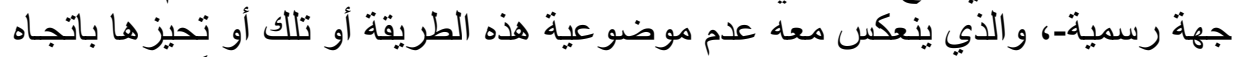

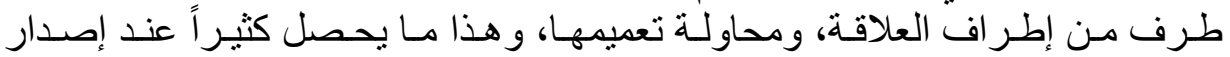
المعايير المحاسبية في العديد من البلدان.

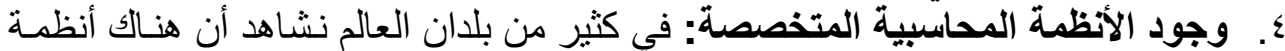

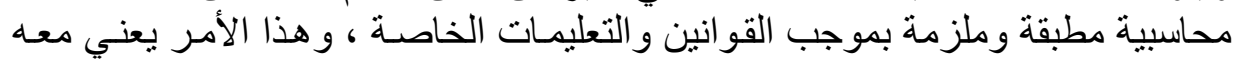

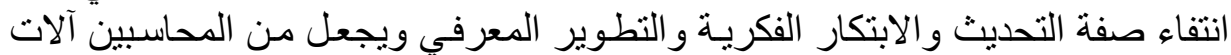
ميكانيكية لتطبيق تلك الأنظمة المتخصصئ.

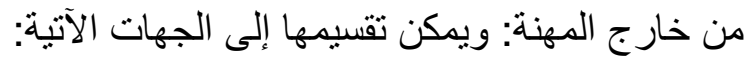

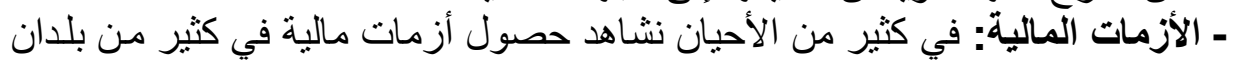

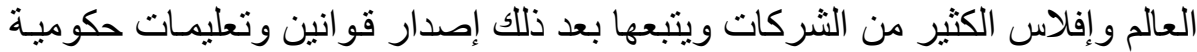

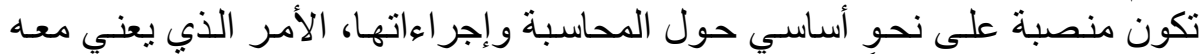

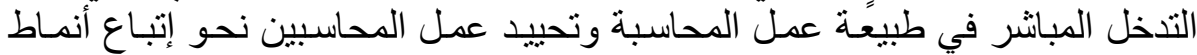

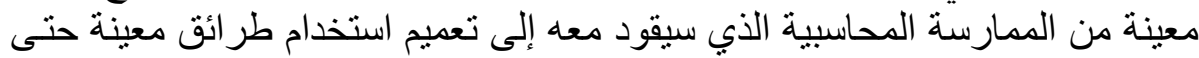

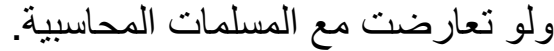

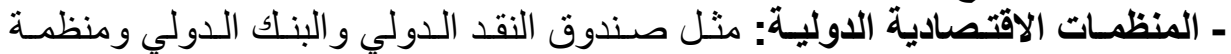

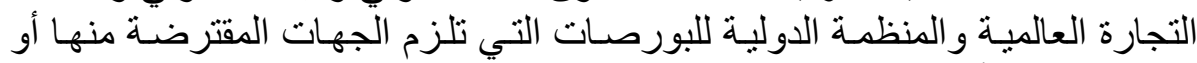

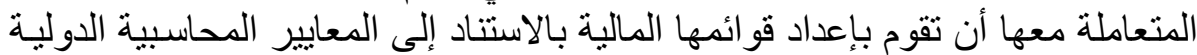

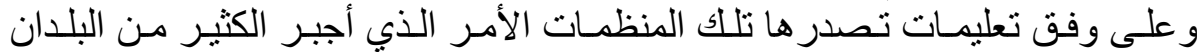
و والمنشآت إلى إتباع تلكات التعليمات.

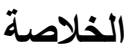
خلص البحث إلى العديد من النتائج :

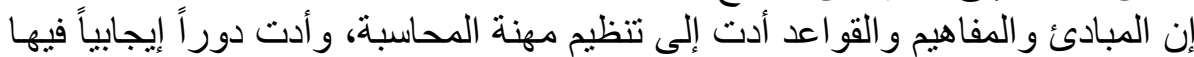

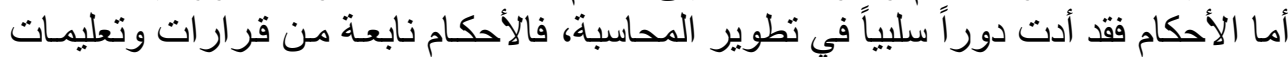

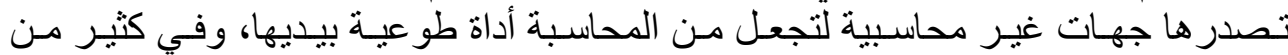


الأحيان نشاهد صور اً سلبية في المحاسبة جر اء استخدام الأحكام على سبيل المثال التحكم

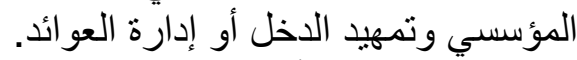
من الملاحظ أن المحاسبة كانت تمارس وفئ وفقاً للمبادئ و المفاهيم المحاسبية، ألا أن هذه أنها

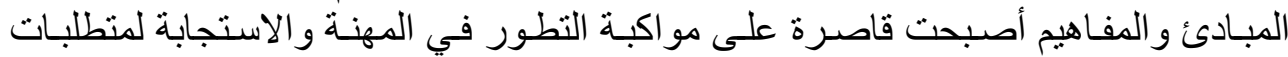

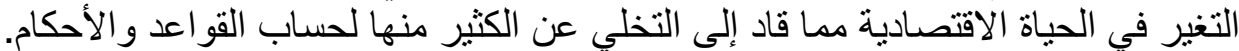
المبادئ و المفاهيم المحاسبية تولدت من التفكير المنطقي المصاحب الماتب للتطبيق أبي أنها

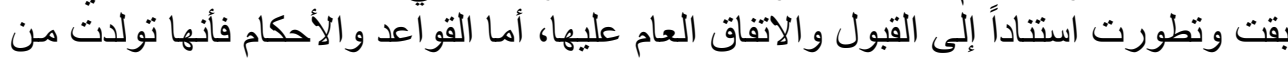

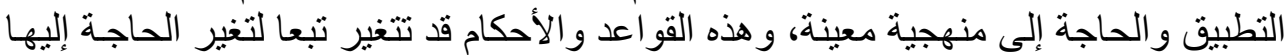

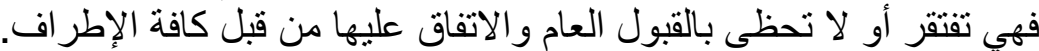

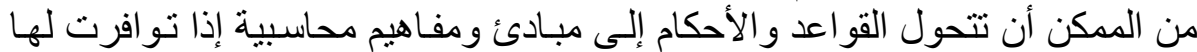

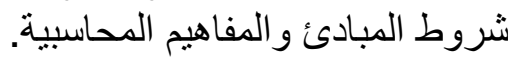

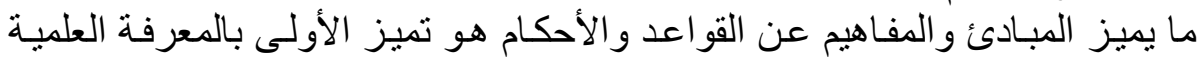

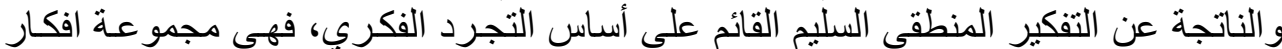

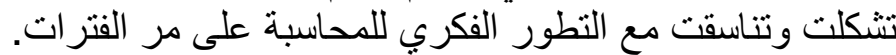

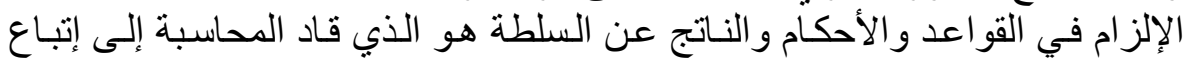

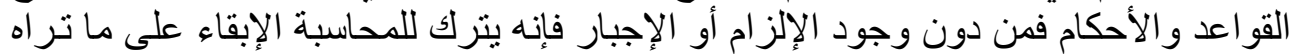

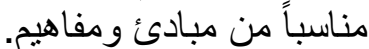

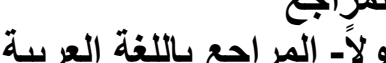 \\ أولاًِ المراجع}

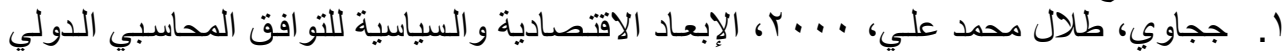

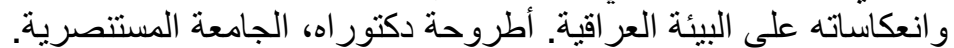

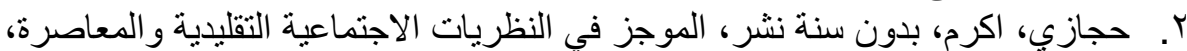
http://ouargla.5forum.info/t177-topic

r. حمدان، مـأمون ، بـدون سنة نشر، مقدمـة عن معايير المحاسبة الدوليـة، جمعيـة المحاسبين

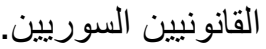

www.philadelphia.edu.jo/courses/accountancy/Files/Accountancy/hi.doc

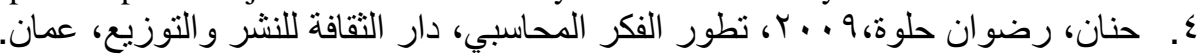

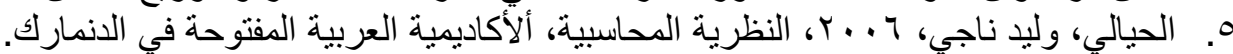

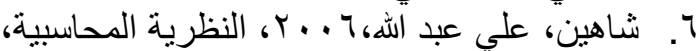
http://www.4shared.com/document/DFNVpcIJ/_online.htm

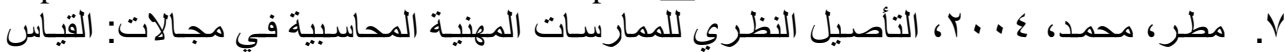

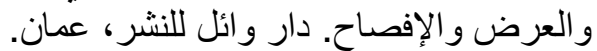

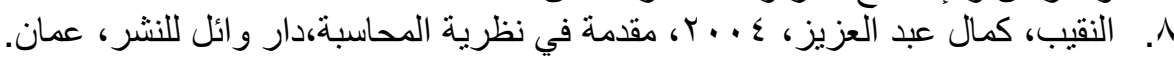

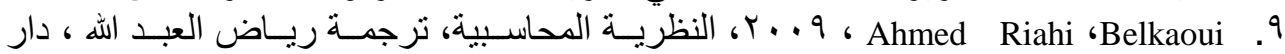

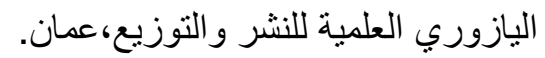

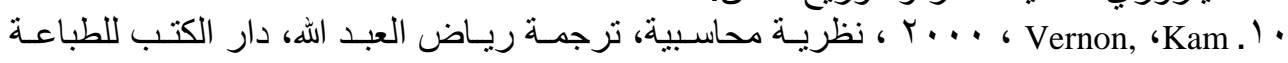

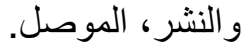

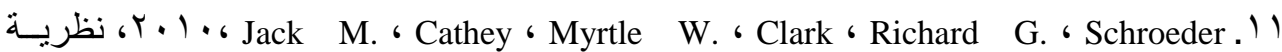

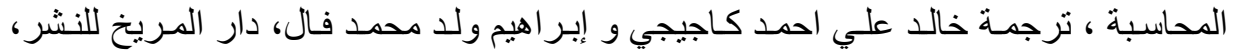


الحبيطي والشمام [rVV]

\section{ثنانياً. المراجع باللغة الاجنبية}

1. Littleton, A. C. 1938. Tests for principles. The Accounting Review.

2.Zeff, Stephen A. 000, Evolution of US Generally Accepted Accounting Principles (GAAP) www.iasplus.com/resource/0407zeffusgaap.pdf

3. Bedford, Norton M., Ziegler, Richard E., 1975, The Contributions of A. C. Littleton to Accounting Thought and Practice, The Accounting Review, vol.L No.3.

4. Shields, John, 2010, International Accounting Standards: Panacea or Problem? http://ethics.davidson.edu/wp-content/uploads/2010/05/Shields-on-internationalaccounting-standards.pdf 